\title{
LEAKING METHANE FROM NATURAL GAS VEHICLES: IMPLICATIONS FOR TRANSPORTATION POLICY IN THE GREENHOUSE ERA
}

\author{
D. G. VICTOR* \\ International Institute for Applied Systems Analysis, A-236I Laxenburg, Austria
}

\begin{abstract}
A model of the U.S. automobile market is used to test the role that natural gas vehicles (NGVs) might play in reducing greenhouse-gas emissions. Since natural gas (primarily methane) emits less $\mathrm{CO}_{2}$ per unit of energy than petroleum products, NGVs are an obvious pathway to lower $\mathrm{CO}_{2}$ emissions. High- and low-demand scenarios are used to forecast the emissions from unrestricted growth and a modest program of conservation, respectively. Based on these scenarios, a reference scenario is developed that projects a possible future path of automobile use and efficiency. It is found that without a dramatic increase in automobile use, fuel consumption and greenhouse-gas emissions from automobiles in the United States will probably decrease in the future, provided that efficiency continues to improve at modest rates. In theory, NGVs can help shift emissions even further down.

A second objective is to quantify the role that leaking methane might play in offsetting some of the greenhouse advantages of NGVs. To do this, a simple atmospheric chemistry model is applied to the reference scenario; several leak rates and feedback factors are used to test the sensitivity of the projected greenhouse forcing from now until 2050. Committed warming beyond 2050 is not included, and the results should be interpreted with that in mind.

It is highly unlikely that switching automobiles from gasoline to natural gas will appreciably lower future greenhouse forcing. Constraints on vehicle miles travelled as well as continued improvements in vehicle efficiency will make a much larger contribution towards controlling global warming.
\end{abstract}

\section{Introduction}

Recent concern over the greenhouse effect has focused attention on opportunities to decrease emissions of greenhouse gases (GHGs) such as $\mathrm{CO}_{2}$ and $\mathrm{CH}_{4}$ (natural gas, methane) and reduce theorized global warming. Switching to natural gasfueled systems is one option because coal and petroleum fuels emit about $75 \%$ and $40 \%$ more $\mathrm{CO}_{2}$, respectively, than natural gas. ${ }^{1}$ Further, natural gas technologies are typically more fuel efficient than their oil- and coal-based counterparts. Published reports, ${ }^{2}$ Congressional testimony, ${ }^{3}$ editorials, ${ }^{4}$ and recent bills ${ }^{5}$ all acknowledge the role that natural gas might play in a plan to cut U.S. GHG emissions. Currently, large $\mathrm{CO}_{2}$ savings are realized through natural gas use instead of oil or coal in space heating, industrial processing, and electricity production. ${ }^{6}$

\footnotetext{
* Current address: Department of Political Science, Massachusetts Institute of Technology, Cambridge, MA 02139, U.S.A.
} 
Ausubel et al. have argued that these savings will increase as natural gas becomes the dominant fuel source in a 'methane economy'?

Natural gas-fueled vehicles (NGVs) have been explored as one such methanebased technology. In the past, NGVs have been considered for local environmental, economic and energy security reasons, ${ }^{8}$ but now NGVs are also considered under a broad program of fuel switching to reduce GHG emissions. ${ }^{9}$ Certainly other automotive technologies - such as hydrogen-fueled and electric vehicles - offer greater promise as long-term greenhouse-reduction measures, but NGVs may exist as a bridge to those new technologies. Also, there are many environmental reasons - aside from the greenhouse effect - why NGVs might become a dominant transportation system since NGVs emit lower amounts of some pollutants than do their conventional gasoline-powered counterparts. Thus one can imagine a number of persuasive arguments why natural gas - and NGVs in particular - will become more widely used. Given that the greenhouse effect will likely be a significant concern for energy policy in the future, this paper examines the role NGVs might play in reducing greenhouse-gas emissions.

The paper is divided into two sections. The first section develops a model of U.S. automobile use and applies a number of NGV switching scenarios to explore the opportunities for greenhouse-gas reductions. For this section, it is assumed that the natural gas recovery and supply system does not leak. The second section addresses the effect of methane leaks using the reference scenario developed in the first section. Methane is a strong greenhouse gas, so even small leaks might be serious greenhouse contributors. Others have argued that the greenhouse benefits of NGVs are robust ${ }^{10}$ - that the $\mathrm{CO}_{2}$ advantages of using NGVs more than outweigh the disadvantages of methane leaks - and one objective of this paper is to challenge those results.

\section{The Model}

The model is structured to project changes in vehicle miles travelled (VMT) and NGV penetration into the market. Efficiency projections are then included and total fuel use is calculated; greenhouse-gas emissions are computed from total fuel consumption and the fuel type. In an effort to put the discussion in perspective, historical trends in all variables have been collected back to $1950 .{ }^{11}$ The model only includes automobiles although opportunities for NGV switching also exist for trucks and buses. The observations presented here for cars probably also apply to other vehicles. The structure is summarized in Figure 1; below, the variables are systematically discussed.

\subsection{Market Growth}

Two scenarios are used for growth of the automobile market; one represents a high energy demand and the other low energy demand that is the result of a modest program of constraining market growth. A reference scenario - between the high- 


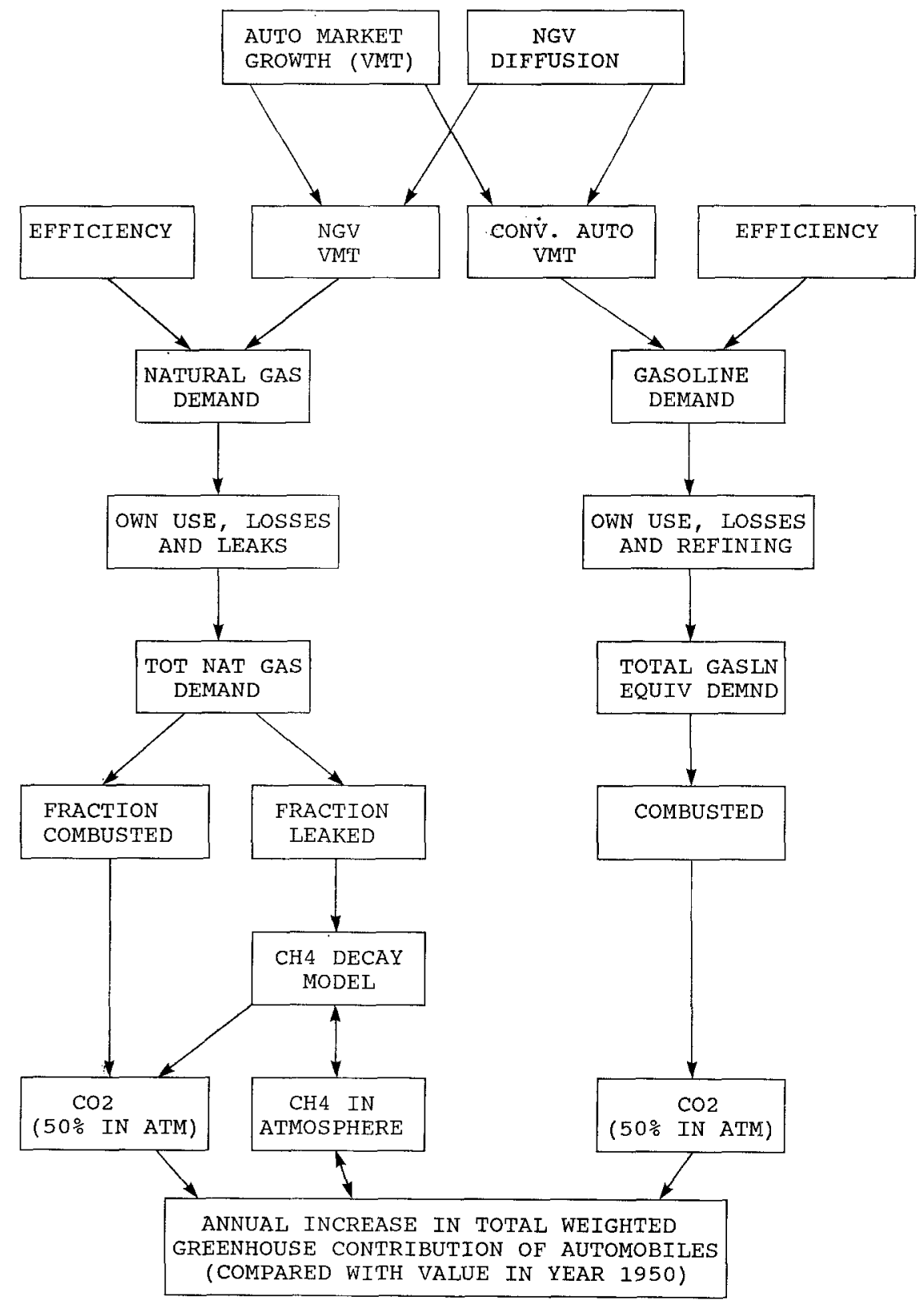

Fig. 1. Structure of the model. Methane feedbacks shown with double arrows.

and low-demand scenarios - is developed as one possible future course of U.S. automobile use and fuel demand.

The high-demand scenario assumes that the VMT will grow as a linear extension of the past. Arguably, growth may be exponential in the future since increases in 
income will make automobiles and automobile fuel more widely available. However, congestion and the availability of public transportation may offset incomebased growth. From 1975 to 1985, tutal highway mileage in the U.S. has remained essentially the same although the number of vehicles and total vehicle miles travelled have increased by $20 \%$ and $33 \%$, respectively. ${ }^{12}$ Over the same period, the number of passenger transit systems (e.g., buses, rail systems, trolleys) has more than doubled, and the number of passengers has increased by $30 \% .^{13}$ Assuming that congestion remains and the expanded use of public transit continues, a highdemand scenario can probably assume no more than linear growth in VMT from past trends.

The low-demand scenario assumes that reductions in VMT growth will slow such that VMT growth is reduced to zero by 2010 . This scenario is a possible result of efforts to decrease automobile use. Concern over energy security and the environmental side-effects of automobile use may generate pressure for such VMT reductions. As discussed later, the market restrictions in this low-demand scenario might be coupled with strong incentives such as higher fuel prices to improve efficiency; high fuel prices will also help limit VMT.

The reference scenario incorporates constraints from both the high- and lowdemand scenarios and assumes that the average use of passenger cars will not increase much beyond current levels of 5271 VMT per person $(8434 \mathrm{~km}$ per person). ${ }^{14}$ The underlying assumption is that for a very affluent society the constraint on automobile use is not economic growth. Instead, there may be physical limits to high VMT growth: at current vehicle utilization of 1.7 persons/vehicle, ${ }^{15}$ the passenger miles travelled (PMT) per person is about $8960 \mathrm{mi}(14336 \mathrm{~km})$. In $1985,66 \%$ of the population held driver's licenses $;{ }^{16}$ on average, each driver would have to operate a vehicle $7990 \mathrm{mi}(12784 \mathrm{~km})$ to achieve total VMT levels. Perhaps only as little as $60 \%$ of the population ( 144 million) is physically fit to drive an automobile legally, ${ }^{17}$ in which case each driver would have to drive $8790 \mathrm{mi}$ $(14064 \mathrm{~km})$. Thus if the average time budget allocated to personal travel does not change much in the future, population might be the growth-limiting factor (especially if congestion favors non-highway modes of travel).

Based on this analysis, the reference scenario assumes that annual VMT growth will gradually reduce from the current average of $2.07 \% / \mathrm{yr}^{18}$ such that by 2000 , VMT growth follows population growth. Note that passenger miles travelled (PMT) per capita might continue to increase under this scenario; indeed, the pressures of congestion and a greater interest in public transportation might favor higher utilization than 1.7 persons per vehicle.

Figure 2 shows the VMT projections from the three scenarios. Figure 3 combines the data into projections for VMT per capita and VMT per potential driver, assuming that the percentage of potential drivers remains about $66 \%$ of the U.S. population. Note the steady decline in VMT per capita for the low-demand scenario: although VMT growth is zero, population continues to grow (except after 2025 when U.S. population is projected to decline $.6 \% / \mathrm{yr}) .{ }^{19}$ 


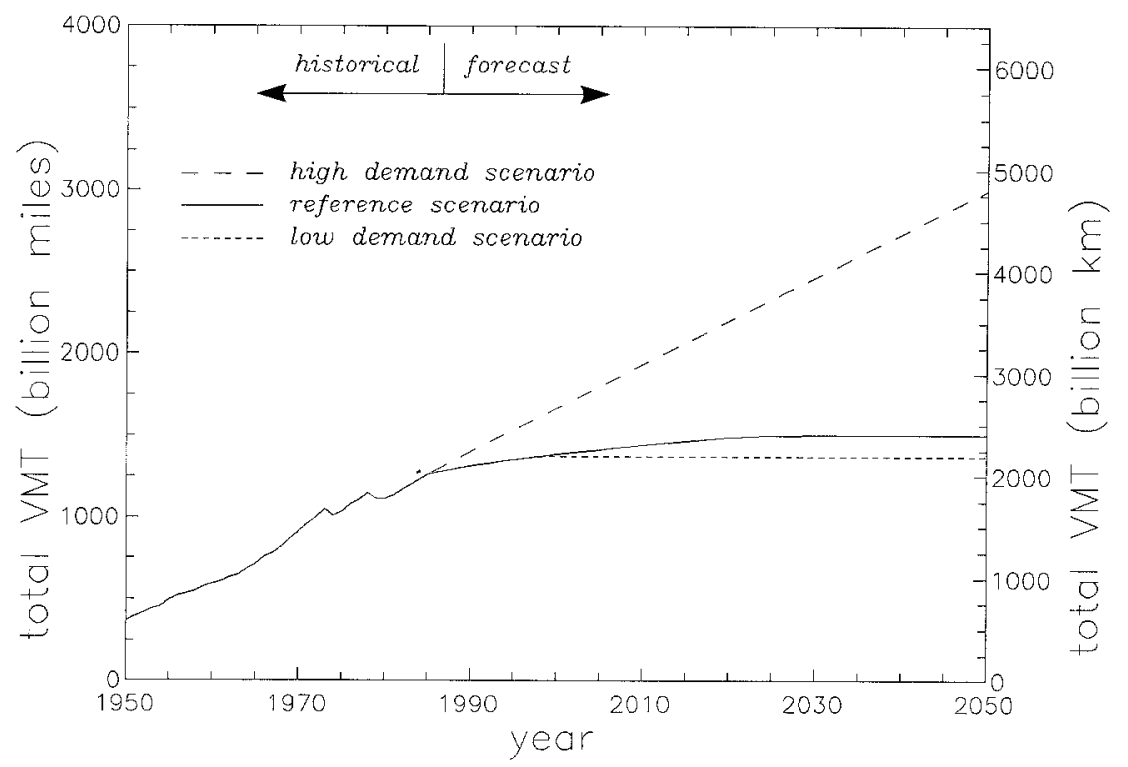

Fig. 2. Projections for total vehicle miles travelled (VMT) in the United States for the high- and lowdemand and reference scenarios (see text).

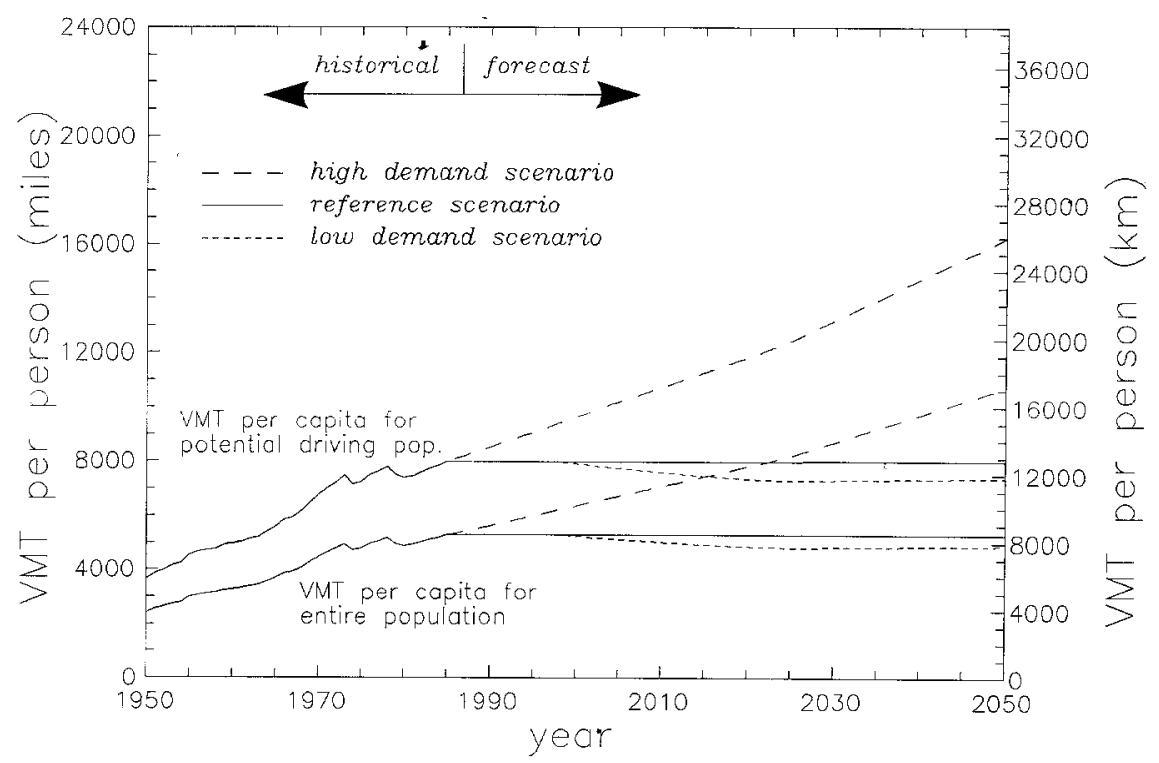

Fig. 3. U.S. VMT per capita for entire population (lower curves) and VMT per capita for estimated potential driving population (upper curves) assuming $65 \%$ of the population can drive a car. 


\subsection{Market Penetration}

Other authors have observed that technologies compete with each other for market share in a manner similar to niche competition between species. ${ }^{20}$ A new technology enters the market with a small share and progressively invades the market following a simple S-shaped logistic curve. ${ }^{21}$ It is assumed that NGVs will penetrate the automobile market in a similar manner.

Since a program of NGV switching would require massive capital expenditures in refueling equipment, natural gas pipelines, and mechanic training, it is not clear what the maximum market penetration might be. Substitution between NGVs and conventional cars would likely be quite easy once the infrastructure is in place, so a continuous range of penetrations is possible.

In an effort to bracket all these possibilities, two market-penetration scenarios are used: one with maximum penetration of $20 \%$, the other with $60 \%$. Market penetration is expressed as the portion of VMT driven by NGVs. The $20 \%$ scenario represents the likely penetration if just business and government fleet vehicles plus a limited number of other automobile users switch to NGVs. The most polluted cities might, for example, institute measures that make NGVs very attractive since NGVs have lower emissions of $\mathrm{CO}$ and non-methane hydrocarbons, both of which are controlled under the National Ambient Air Quality Standards. ${ }^{22}$

The $60 \%$ scenario reflects a likely result from a broader NGV switching pro-

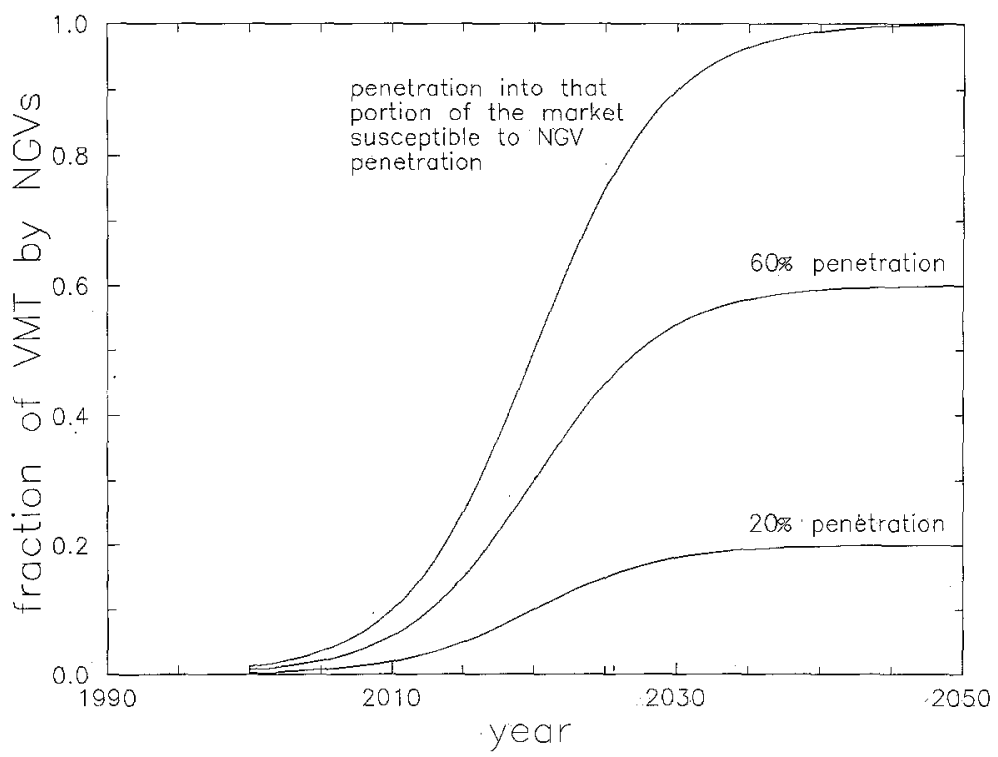

Fig. 4. Hypothetical curves for diffusion of NGVs into the U.S. automobile market. Vertical axis is the fraction of U.S. VMT driven by NGVs. Two scenarios $-20 \%$ and $60 \%$ diffusion - are used; a curve for $100 \%$ diffusion (i.e., diffusion into that portion of VMT that is susceptible to NGV diffusion) is also shown. 
gram. For example, national incentives might exist that favor NGV use for environmental reasons (perhaps even in response to the greenhouse effect). Nonetheless, intercity and rural automobile transport will probably remain reliant upon gasoline; for this reason, a somewhat arbitrary upper limit of $60 \%$ penetration is set. However, higher penetration limits may result if natural gas refueling stations become widespread, prices for natural gas remain competitive with gasoline, and consumers do not believe NGVs will become obsolete. Also, if natural gas is widely used in other areas (e.g., electricity generation and heating) then the large supply network may assist high market penetration of NGVs by providing some of the pipeline infrastructure required for refueling stations.

Figure 4 summarizes the changing market shares for the $20 \%$ and $60 \%$ scenarios. The most rapid period of diffusion (from $10 \%$ potential market share to $90 \%$ ) is expected to take 20 years ( $\Delta t=20 \mathrm{yr}$ ); complete diffusion (from $1 \%$ to $99 \%$ ) takes twice that time, or 40 years. This is less rapid than for other technological shifts: catalytic converters diffused into the U.S. market with $\Delta t=13 \mathrm{yr}^{23}$ and data on the survival rate of passenger vehicles supports a diffusion rate of about $\Delta t=10 \mathrm{yr}^{24}$ However, changes in the refueling infrastructure as well as necessary shifts in consumer behavior make a somewhat slower diffusion more likely.

\subsection{Efficiency}

Predicting future efficiencies is quite difficult since the future will, most likely, not follow past trends. Since 1973, improvements in automobile efficiency have been dramatic, and if the addition of energy-intensive pollution-control equipment is controlled for, the results have been even more impressive. These improvements are the result of consumer demands for more efficient cars after the 1973 oil shock, but the U.S. policy of setting minimum efficiencies for new cars has also contributed. It is not clear how any of these variables will fluctuate in the future. Furthermore, other factors such as consumer tastes and levels of vehicle ownership are also important for long-term projections since they affect the character of the fleet which, in turn, affects overall efficiency.

For the high-demand scenario, average fleet efficiency is assumed to grow at current levels through 1995 as the least efficient, older cars are retired from the fleet. Thereafter, efficiency growth decreases to zero and after 2000 there are no improvements in efficiency (i.e., efficiency remains at the 2000 level of $27 \mathrm{mi} \mathrm{gal}^{-1}$,

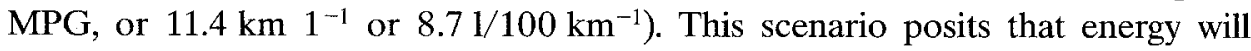
remain relatively cheap and incentives to improve efficiency will be nonexistent. This is consistent with the other high-demand assumptions of unbounded automobile and fuel use.

The low-demand scenario assumes that restrictions on market growth will be accompanied by strong incentives to improve efficiency. By 2050 the average fleet efficiency is assumed to increase to 60 MPG $\left(26 \mathrm{~km}^{-1}\right.$, or $\left.3.9 \mathrm{l} / 100 \mathrm{~km}^{-1}\right)$. This growth is less rapid than for the period 1975-1985, but it is assumed that the most 
dramatic efficiency improvements such as the reduction in the sales of very large cars have already happened. ${ }^{25}$ Nonetheless, the low-demand efficiency assumptions require substantial improvements in all automobile systems and probably also require shifts in consumer tastes to favor smaller, lighter cars. However, the scenario is not entirely unrealistic since vehicles that perform at $50 \mathrm{MPG}\left(21 \mathrm{~km} \mathrm{1}^{-1}\right.$, or $4.7 \mathrm{l} / 100 \mathrm{~km}^{-1}$ ) are available today; presumably higher efficiencies will result from 60 years of future innovation, provided that proper incentives exist. Notably, achieving these country-wide efficiencies will probably require much higher fuel prices.

The reference scenario assumes that pressure to improve efficiency will continue through 2050 but that the improvements will be less dramatic than for the lowdemand scenario. By 2050 , fleet efficiency is 45 MPG $\left(19 \mathrm{~km} 1^{-1}\right.$, or $5.21 / 100$ $\mathrm{km}^{-1}$ ). As assumed with the other scenarios, the overall fleet efficiency will continue to increase along the average trends for the period $1975-1985$ as the major post-shock efficiency improvements filter through the fleet. After 1995, efficiency is assumed to increase by $1 \% / \mathrm{yr}$, or about half the efficiency growth rate for $1975-$ 1985.

A major challenge to the reference scenario's efficiency assumption is the recent trend that the efficiency of new cars sold is decreasing after two years of stagnation. ${ }^{26}$ However, over the long run, such cyclic behavior is expected.

An earlier version of this model attempted to study fuel consumption in more detail by focusing on the efficiency and sales of new cars; based on survival and utilization rates, total VMT and fuel use were, theoretically, calculated. ${ }^{27}$ However, the attempt failed to make realistic long-term projections because the dynamics of survival and scrappage rates are not well understood; the number of free parameters is unmanageable. ${ }^{28}$ For this reason, the current model explicitly avoids the question of how many cars will be on the road and focuses only on VMT and fleet average efficiency. However, the per capita ownership of cars will probably increase from 1985 levels of 561 cars per 1000 to about 700 cars per $1000 .^{29}$ In 1985 , Connecticut had an average ownership level of 745 automobiles per 1000 population, so even higher levels of vehicle ownership are not impossible. Survival rates may decrease with affluence; if so, the fleet will be newer and (perhaps) more efficient than the projections here. This should be kept in mind when analyzing the results.

Efficiency of natural gas vehicles is highly dependent upon their basic design. For a dual-use vehicle (i.e. runs on both gasoline and natural gas) there may be no gain in fuel efficiency (e.g., km per joule of energy) over a purely conventional fuel vehicle. ${ }^{30}$ However, this analysis assumes that a vehicle optimally designed for compressed natural gas (CNG) will ultimately be $15 \%$ more efficient than a gasolinefueled vehicle for two reasons: (1) natural gas has a higher octane number so it can burn more efficiently; ${ }^{31}$ and (2) NGVs may ultimately require less pollution-control equipment, at least for $\mathrm{CO}$ emissions, since natural gas has a lower carbon content than conventional fuels. This assumes that $\mathrm{NO}_{x}$ emissions and $\mathrm{NO}_{\mathrm{x}}$-control equip- 
ment will be about the same as for conventional-fueled vehicles, but even this is not clear since the $\mathrm{NO}_{x} / \mathrm{CO}$ tradeoff may favor less $\mathrm{NO}_{\mathrm{x}}$-control equipment for NGVs. ${ }^{32}$ It is possible to imagine an ideal NGV which might have higher efficiency than the case used here, but with current NGVs this is probably the most reasonable case. However, the NGV fleet may initially be much more fuel efficient than the conventional gasoline-powered fleet because the NGVs will be new (assuming they are dedicated NGVs and not converted, existing gasoline automobiles). If this is the case, the model will overestimate fuel consumption by a progressively decreasing percentage during the early ( $10-15$ years) period of NGV use.

If liquified natural gas vehicles (LNGVs) become popular instead of compressed natural gas, the overall efficiency will likely be $5 \%$ to $10 \%$ lower than for NGVs due to the energy required for fuel liquefaction. The exact efficiency loss depends on the design tradeoff between fuel pressure and temperature in the LNGV storage tanks.

The efficiency of conventional gasoline-powered vehicles and NGVs is summarized in Figure 5. Note that in the past, efficiency has not always increased, so even the high-demand assumption that efficiency will remain level is suspect, especially if real energy prices decline as they did up to the oil shock of 1973. Also note the vigorous improvements in efficiency since 1973.

As mentioned before, most of the greenhouse advantages of NGVs come from the lower $\mathrm{CO}_{2}$ emissions per unit of energy. This advantage for natural gas is in addition to the greater energy efficiency just discussed.

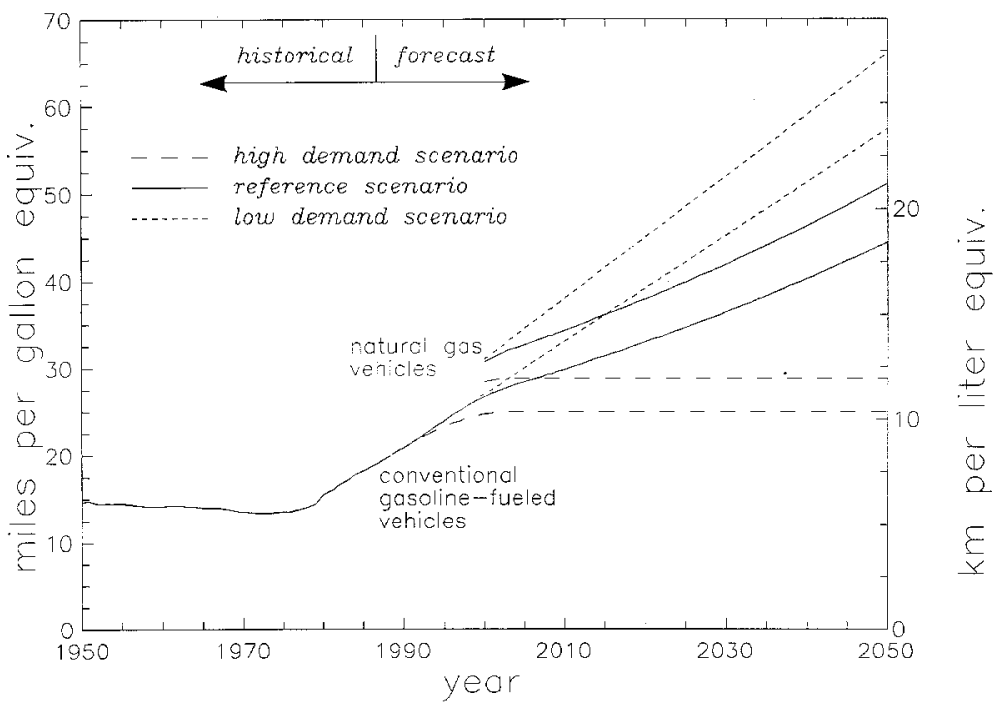

Fig. 5. Projected efficiency of conventional gasoline-powered fleet and NGVs in the U.S. for the highdemand, low-demand, and reference scenarios. For reference, historical data on the efficiency of the total automobile fleet is also shown. NGV efficiencies were converted to MPG equivalents using the heat content of natural gas and gasoline along with the assumption that NGVs will consistently be $15 \%$ more efficient than conventional gasoline-powered vehicles. 


\subsection{Pipeline Operations and Refining}

The combination of market growth, NGV penetration, and efficiency lead to total fuel consumption by fuel type. Before calculating greenhouse-gas emissions, the model also includes energy requirements (and, thus, $\mathrm{CO}_{2}$ emissions) for refining and 'own use' for fossil-fuel recovery, pipeline operations, other transport requirements, and refining. For gasoline production, it is assumed that $8 \%$ of each ton of oil is burned in refining and in oil-recovery operations, releasing $\mathrm{CO}_{2} \cdot{ }^{33} \mathrm{An}$ additional $2 \%$ is consumed in pipeline and non-pipeline transport of oil products. For natural gas, about $9 \%$ of total gas consumption is for 'own-use', according to EIA (Energy Information Administration) statistics. ${ }^{34}$ OECD data support a lower number, $5.5 \%$, so this model, which uses the EIA data, may slightly overestimate $\mathrm{CO}_{2}$ emissions from NGVs if the OECD data are closer to the truth. ${ }^{35}$ In general, 'own use' energy requirements are assumed to be similar for petroleum and natural gas operations (i.e., on the order of $10 \%$ ). ${ }^{36}$

$\mathrm{CO}_{2}$ emissions from industrial activity required to build the automobiles themselves are not included. This omission probably exists systematically for NGVs and gasoline passenger cars so it will not affect the comparisons.

\subsection{Results}

Figure 6 summarizes the total energy use for the permutations of three growth scenarios (high and low demand and the reference case) and three penetration scenarios $(0 \%, 20 \%$, and $60 \%$ VMT by NGVs). Note that in the recent past, energy

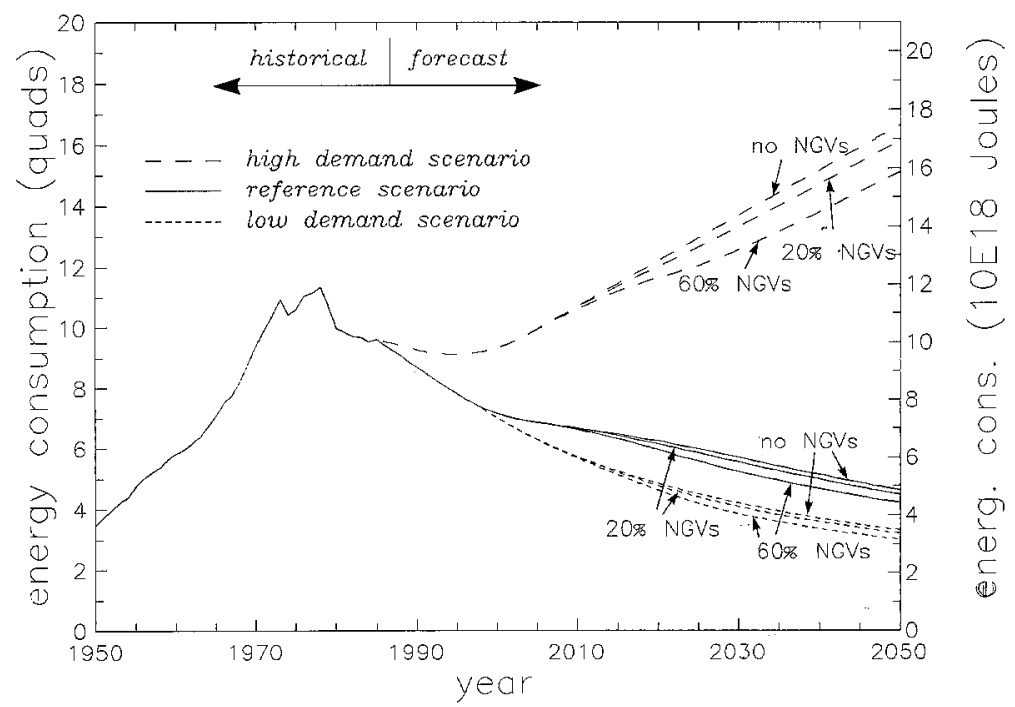

Fig. 6. Annual U.S. total energy consumption for permutations of three growth/efficiency scenarios (high and low demand and reference) and three NGV diffusion scenarios $(0 \%, 20 \%$, and $60 \%$ ). 
consumption has been decreasing although VMT has, on average, been increasing (Figure 2). Since 1975, efficiency has grown much faster than VMT; both the reference and low-demand scenarios assume that this trend will continue in the future. For the high-demand scenario, VMT will grow much faster than efficiency, but due to the major efficiency improvements since 1975, total fuel use in 2050 is only $50 \%$ higher than 1975 levels whereas VMT has increased $60 \%$ over the same period. Thus even if efficiency does not improve over the next century, the oil shock will continue to influence fuel consumption patterns by raising the average economy of the fleet to a new plateau (assuming it does not decline again).

$\mathrm{CO}_{2}$ emissions are calculated from total energy consumption using the $\mathrm{CO}_{2}$ emission factors for gasoline and natural gas; ${ }^{1}$ an amount equivalent to $50 \%$ of fossil-fuel emissions is assumed retained in the atmosphere for the period of the projections (i.e., until at least 2050). This has been called the 'marginal airborne fraction'. The value of $50 \%$ is taken from Bolin, whose estimate of the marginal airborne fraction is based on a review of the carbon-cycle literature. ${ }^{37}$ Many other energy projections have also used a value around $50 \%$, so the projected $\mathrm{CO}_{2}$ concentrations presented here are compatible with past work in this area. ${ }^{38}$ Because the projections here are relatively short (60 years) compared with the mean residence time of atmospheric $\mathrm{CO}_{2}$ - estimated at $230^{39}$ or $500^{40}$ years - no long-term 'seepage' factor is used to account for the slow absorption of $\mathrm{CO}_{2}$ into the deep oceans. ${ }^{41}$ The marginal airborne fraction is held constant at $50 \%$ with the assumption that the seepage is built in (this is the same method used by Bolin in projecting atmospheric $\mathrm{CO}_{2}$ to the year 2100 , much further than the current study).

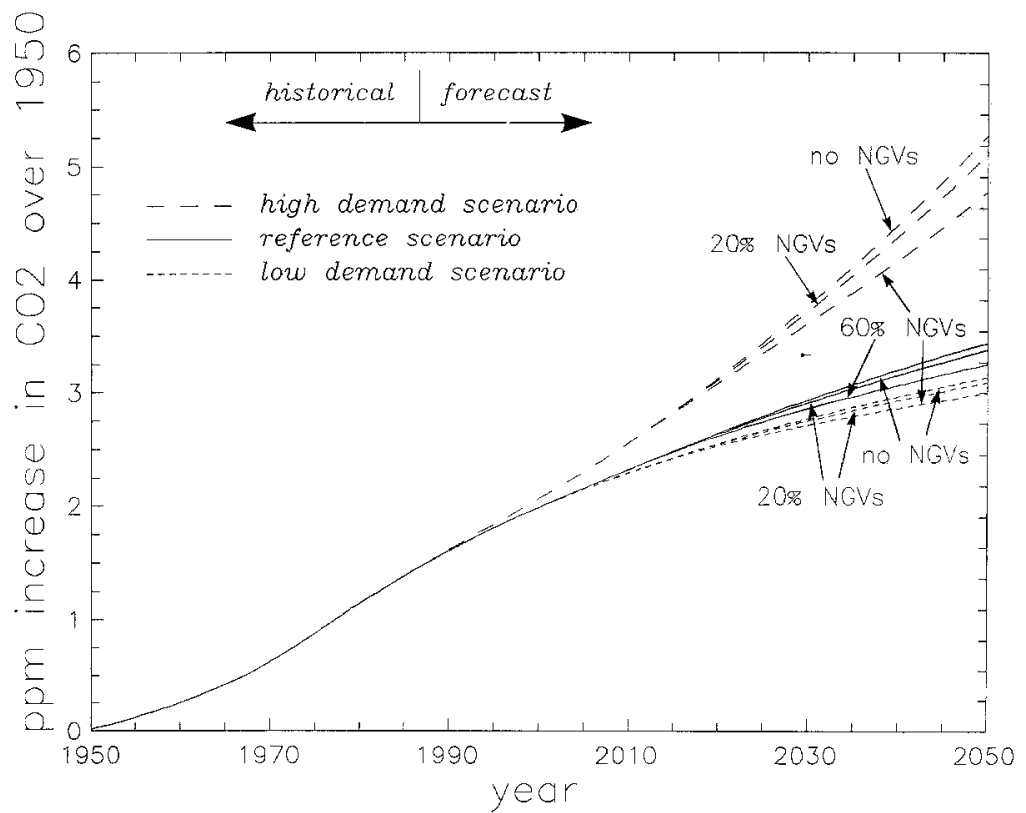

Fig. 7. Increase in atmospheric $\mathrm{CO}_{2}$ concentration (in parts per million) since 1950 due to automobile use in the United States. 
TABLE I: Major greenhouse-related uncertainties that affect this model

Parameter Range Notes

\section{Carbon dioxide:}

Atmospheric retention of anthropogenic $\mathrm{CO}_{2}$ emissions ('marginal airborne fraction')
$30-70 \%$

(50\% used here)
May change in the future if net sinks do not change in proport. to net $\mathrm{CO}_{2}$ emissions. May be much lower if current $\mathrm{CO}_{2}$ source from deforestation is very large.

Methane:

Mean residence time of $\mathrm{CH}_{4}$ in the atmosphere

$8-14$ years

Feedback factor for chemical/ radiative feedback

Methane factor (for converting ppm $\mathrm{CH}_{4}$ to equiv. of ppm $\mathrm{CO}_{2}$ ) Such a feedback is estim. and included in model

Amplifies effective emissions of $\mathrm{CH}_{4}$.

Includes radiative effects of trop. $\mathrm{O}_{3}$ and stratospheric water vapor. Amplifies the methane factor described below.

Uncertainty is quite small. May be smaller in the future due to band
Feedback factor for $\mathrm{OH}$ depletion

May increase due to $\mathrm{OH}$ feedback. saturation. Is amplified by the chemical/radiative feedbacks described above.

Methane sources:

Total methane source

400-640 Tg annually

$10-32 \%$

$\%$ from 'old' sources (determined isotopically)

Amount of fossil-fuel-derived $\mathrm{CH}_{4}$ is from natural sources (i.e., not directly related to mining or total energy production)

All 'old' methane leaks due to 50-95 Tg energy production $(\mathrm{coal}+$ oil + nat. gas)

Methane from coal mining annually

$25-45 \mathrm{Tg}$ annually
$540 \mathrm{Tg} / \mathrm{yr}$ used in this study (500 $\mathrm{TG} / \mathrm{yr}$ is quasi stdy. state source; $40 \mathrm{Tg} / \mathrm{yr}$ yields the $1 \%$ annual incr. in atm. $\mathrm{CH}_{4}$.

$22 \%$ for this study, including $33 \mathrm{Tg}$ from 'old' biol. sources.

$33 \mathrm{Tg}$ of 'old' sources assumed from biology in this study. The rest assumed proportional to respective energy production. Biol. sources or natural fossil based seeps may be larger, so problem of $\mathrm{CH}_{4}$ leaks from energy prod. may be overstated.

May be lower if other methane sources release substantial quan. of 'old' methane.

Currently believed to be about $35 \mathrm{Tg}$. 
Table I (continued)

\begin{tabular}{lll}
\hline Parameter & Range & Notes \\
\hline Methane from natural gas and oil & $\begin{array}{l}25-50 \mathrm{Tg} \\
\text { annually }\end{array}$ & $\begin{array}{l}\text { Currently believed to be about } \\
45 \mathrm{Tg} .\end{array}$ \\
$\begin{array}{l}1-5 \% \\
\text { annually }\end{array}$ & $\begin{array}{l}\text { Calculated at } 3.6 \% \text { from atm. data; } \\
\text { industry data support lower rate. }\end{array}$ \\
$\begin{array}{l}\text { Amount of methane from natural } \\
\text { gas/oil is from oil }\end{array}$ & $?$ & $\begin{array}{l}\text { This study uses } 0 \mathrm{Tg}, \text { but the } \\
\text { model is tested at } 10.6 \mathrm{Tg} \text { and the } \\
\text { results remain about the same. }\end{array}$ \\
\hline
\end{tabular}

There is considerable uncertainty here since the net sources and net sinks of atmospheric $\mathrm{CO}_{2}$ are not well understood. Further, the marginal airborne fraction is scenario dependent since changes in atmospheric $\mathrm{CO}_{2}$ affect chemical buffering in the oeans and, thus, the fraction of emissions that remain airborne. For example, if total $\mathrm{CO}_{2}$ emissions decrease, the marginal airborne fraction will decrease as well. ${ }^{42}$

Figure 7 summarizes the increase in greenhouse forcing since $1950 .{ }^{43} \mathrm{CO}_{2}$ is expressed as the increase in parts per million (ppm) atmospheric $\mathrm{CO}_{2}$ concentration since 1950 attributable to automobile use in the U.S. The atmospheric content of $\mathrm{CO}_{2}$ - because it is a cumulation of many years' emissions - responds sluggishly to changes in the pattern of $\mathrm{CO}_{2}$ emissions. The curve rises exponentially from 1950 to 1975 as VMT grew rapidly while efficiency gradually decreased. Since $1975, \mathrm{CO}_{2}$ concentrations from the U.S. automobile sector have grown linearly. Note that by 1988, atmospheric $\mathrm{CO}_{2}$ concentrations had increased about $1.5 \mathrm{ppm}$ since 1950 due to automobile use in the U.S. alone; the total increase (due to all $\mathrm{CO}_{2}$ emissions worldwide, including deforestation) over that period was about $35 \mathrm{ppm}$.

According to these calculations, NGVs can make only a small difference in $\mathrm{CO}_{2}$ concentrations. Compared with zero NGV penetration, projected increases in atmospheric $\mathrm{CO}_{2}$ due to passenger vehicles in the U.S. are $4 \%, 5 \%$, and $10 \%$ lower for $60 \%$ penetration in the low-demand, reference, and high-demand scenarios, respectively. Over time, the savings increase. NGVs are slightly more efficient than conventional gasoline-powered vehicles so they require less energy (Figure 6), but the lower $\mathrm{CO}_{2}$ emission factor for natural gas yields the largest savings. Nonetheless, the combination of the two can yield only modest changes in atmospheric $\mathrm{CO}_{2}$.

The most dramatic differences in atmospheric $\mathrm{CO}_{2}$ come from different fuelconsumption patterns, not NGV switching. Atmospheric $\mathrm{CO}_{2}$ from the highdemand scenario is nearly $70 \%$ higher than the low-demand scenario and $60 \%$ higher than the reference scenario. This paper does not address the economics of fuel switching under these three scenarios, but it appears that market constraints coupled with efficiency improvements may offer larger opportunities for green- 
house-gas reductions than do NGVs themselves. Nonetheless, a program of NGV switching may help reduce greenhouse-gas emissions, and other benefits in lower urban pollution may favor NGVs as well.

\section{The Problem of Methane Leakage}

The results are less favorable for NGVs if the effects of leaking methane are included, since only small emissions of methane can have a large effect on total greenhouse heat trapping. On a molecular basis, the direct greenhouse forcing from methane is about 26 times that of $\mathrm{CO}_{2} \cdot{ }^{44}$ Methane emissions may also yield feedbacks due to altered tropospheric chemistry or stratospheric water vapor, which could enhance the direct greenhouse forcing of methane and the abundance of methane in the atmosphere. (Direct emissions of $\mathrm{N}_{2} \mathrm{O}$ are not considered in this study because they are no longer considered significant. ${ }^{45}$ )

This section will expand the model to include methane leaks. The discussion is divided into five sub-sections: (1) presentation of the model used to calculate the atmospheric concentration of methane which is the result of past years' emissions; (2) estimation of possible current and future natural gas leaks; (3) discussion of the character and magnitude of various feedbacks that may enhance the direct effects of methane emissions; and (4) presentation of results.

A fifth sub-section on the role of methane leaks from the oil production is also included at the end. This source of methane is non-trivial and presents complicated accounting problems since some natural gas production is associated with oil production and it appears that leaks from such associated production are relatively large.

As discussed throughout this section, a number of variables are highly uncertain; these uncertainties are reviewed in Table I. Two main uncertainties - the leak rate and the strength of various feedbacks - are explored through the use of three scenarios. One scenario will represent the best case for NGVs, one will represent the worst case, and a third intermediate scenario is derived with values between the other, extreme cases.

\subsection{Computing the Greenhouse Forcing of Atmospheric Methane}

Any discussion which compares relative greenhouse forcing of $\mathrm{CO}_{2}$ and $\mathrm{CH}_{4}$ (as this one does) must account for the different atmospheric dynamics of the two gases. This will allow computation of the average annual atmospheric concentrations (as distinct from emissions) of the $\mathrm{CO}_{2}$ and $\mathrm{CH}_{4}$ due to past emissions of these gases. The gases are then compared on the basis of concentration using the $26: 1$ ratio.

As discussed earlier, atmospheric $\mathrm{CO}_{2}$ is modelled using the airborne fraction method. A first-order attempt at including the atmospheric chemistry of atmospheric methane is made by assuming a well-mixed atmosphere and by simplifying 
methane leaks to a single emission each year. After release to the atmosphere, emissions from any year $t_{0}$ are removed through reaction with $\mathrm{OH}$ radicals in the troposphere:

$$
\mathrm{CH}_{4}+\mathrm{OH} \rightarrow \mathrm{CH}_{3}+\mathrm{H}_{2} \mathrm{O}
$$

The shape of the curve is exponential, and the rate of removal is reflected in the mean residence time of methane in the atmosphere $\left(10\right.$ years ${ }^{46}$ ). At time $t_{10}, 1 / \mathrm{e}$ (or $37 \%$ ) of the amount emitted at time $t_{0}$ will remain in the atmosphere. At any year, $t$, the atmospheric concentration of methane is the sum of the methane remaining in the atmosphere (i.e. not reacted) from emissions in the years $t, t_{-1}, t_{-2}, t_{-3}$, etc. Upon reaction, the methane is assumed oxidized to $\mathrm{CO}_{2}$ and is treated as a $\mathrm{CO}_{2}$ emission.

The model described here computes the atmospheric retention of $\mathrm{CO}_{2}$ and $\mathrm{CH}_{4}$ quite differently. An amount equivalent to $50 \%$ of each year's $\mathrm{CO}_{2}$ emissions is assumed to accumulate in the atmosphere. For methane, there is no inherent accumulation since a decay function is built into the model. It would be possible to derive a curve for $\mathrm{CO}_{2}$ that is similar to the one just described for methane. However, there is considerable uncertainty in estimating the mean residence time of $\mathrm{CO}_{2}$ in the atmosphere; also, any single 'residence time' for $\mathrm{CO}_{2}$ would be misleading. ${ }^{47}$

The intention here is simply to show and compare the greenhouse curves into the near future ( 60 years from now). This is why the greenhouse is shown dynamically on graphs rather than as a simple back-of-the-envelope calculation that might integrate all future global warming from current emissions into a single index. The advantage of the airborne fraction method is that it seems to accurately describe the current balance between sources and sinks of $\mathrm{CO}_{2}$ and, thus, the observed rise in atmospheric $\mathrm{CO}_{2}$ concentrations. The disadvantage is that by stopping the graphs in 2050 , the analysis here inherently ignores future warming from long-lived gases (i.e., $\mathrm{CO}_{2}$ ). Other authors have chosen to model $\mathrm{CO}_{2}$ with a decay function using a variety of atmospheric lifetimes; ${ }^{48}$ comparisons of different studies should recognize the importance of these methodological differences.

\subsection{Methane Leak Rates}

Estimating the current leak rate is quite difficult and highly contentious. Essentially two methods are available for computing leak rates. One way is to start with isotopic and other data on the global sources of atmospheric methane and work backwards to yield an estimate for worldwide leak rates. For this exercise, the methane budget of Cicerone and Oremland ${ }^{49}$ is adopted. Globally averaged for the period 1978-1987, methane concentrations were $1680 \mathrm{ppb}$ (parts per billion) and were increasing by about $16 \mathrm{ppb} / \mathrm{yr}^{50}$ The estimated annual methane source is $540 \mathrm{Tg}$ $\left(540 \times 10^{12} \mathrm{~g}\right)$, of which it is assumed that about $22 \%(119 \mathrm{Tg})$ is 'dead' as determined by isotopic analysis; however, some measurements suggest the sources of 
such 'old' methane may be much larger. ${ }^{51}$ Of the $119 \mathrm{Tg}$, the Cicerone and Oremland budget assigns $33 \mathrm{Tg}$ and $5 \mathrm{Tg}$ to natural wetlands and methane hydrates, respectively. The remaining $\approx 80 \mathrm{Tg}$ is assumed from fossil-fuel recovery: $35 \mathrm{Tg}$ are assumed from coal-mining activity and the rest $(45 \mathrm{Tg})$ from natural gas drilling, transmission, and venting. Based on 1985 worldwide natural gas use of $1.71 \times$ $10^{12} \mathrm{~m}^{3}(1230 \mathrm{Tg}),{ }^{52}$ the average leakage rate is computed at about $3.6 \%$. As outlined in Table I, there are many uncertainties. For example, it is not clear how to apportion the 'dead' carbon among the various potential sources. Furthermore, the $45 \mathrm{Tg}$ attributed to natural gas leaks may not be entirely proportional to natural gas production since some sources may be leakier than others. All of these uncertainties affect the calculations, especially the average leak rate assigned to worldwide natural gas activities.

The other method is to estimate leak rates by direct measurement of gas fluxes from wellheads, pipelines, distribution systems, and end users. However, the potential sources of such leaks are highly dispersed and thus difficult to measure accurately. As part of a California rate filing, Pacific Gas and Electric found that leaks from its gas distribution pipelines were substantially below $1 \%$ and implied that leak rates would decrease in the future.$^{53}$ Arthur D. Little, in a 1989 study for Ruhrgas A.G., found that the leak rate for all gaseous hydrocarbon emissions was about $1 \%$; the methane leak rate was estimated at $0.53 \%$ of world natural gas production. ${ }^{54}$ The American Gas Association has estimated methane releases to the atmosphere at $1.25 \%$ of U.S. production. ${ }^{55}$ OECD statistics suggest that 'unaccounted for' gas is $2.9 \%$ of production; EIA data for 'unaccounted for' (UAF) gas are higher, about $4 \% .{ }^{56}$ However, it is not clear what fraction of UAF gas is actually released to the atmosphere and what is due to measurement, accounting, or other errors. ${ }^{57}$

In sum, there is considerable disagreement on the issue of leak rates. Some of the difference between the two methods may be due to sampling. In situ data only exist for some of Western Europe and North America, so other large gas producers for which there is little or no reliable data (especially the Soviet Union and Eastern Europe) may have high leak rates which offset low leak producers. If this is the case, globally averaged leak rates would be higher than suggested by U.S. and West European data. Still, if Western leaks are $\approx 1 \%$ then leaks from other areas would have to be much higher (e.g., $10 \%$ or even higher) than in the West if the $3.6 \%$ figure derived from atmospheric data is correct. Alternatively, leak rates may simply be higher than reported by the Western gas industry. This is because there is very little data on end-user leaks, which may be large; similarly, there is little data on leaks from low-pressure end-distribution systems. In any case, all the data have considerable uncertainties that may account for much of the inconsistency. More work on this problem is currently underway. ${ }^{58}$

A best-case scenario for NGVs assumes that leak rates are about $1 \%$; this is based on the assumption that natural gas recovery, pipeline, and distribution leaks are low and that NGV-related leaks will be low. A worst-case scenario uses leak 
rates of $5 \%$ on the assumption that current leak rates are much higher than estimated by the gas industry; perhaps they are even higher than estimated through the atmospheric data. Further, there may be considerable leaking from NGV refueling and the NGVs themselves. Automobile accidents, poor maintenance, tailpipe methane emissions, and tank purges will all increase atmospheric release of methane and thus contribute to the leak rate. These NGV-related leaks may be large, in addition to large wellhead and pipeline leaks.

An intermediate scenario uses a leak rate of $2.5 \%$, somewhere between the gasindustry estimates, which cluster near $1 \%$, and the atmospheric data, which suggest leak rates over $3 \%$.

\subsection{Feedbacks}

In addition to direct effects on climate, emissions of methane will also have indirect effects on climate and atmospheric chemistry that will positively feed back on the initial climatic effects. Primarily, there are three feedbacks. First, since methane reacts with and depletes $\mathrm{OH}$ (required for reaction 1), methane emissions extend the lifetime of methane in the atmosphere and lead to further increases in methane concentration. Second, the oxidation of methane also increases tropospheric ozone concentrations, which increases greenhouse forcing since ozone is a greenhouse gas. Third, methane contributes to stratospheric water vapor and increases greenhouse forcing since water vapor is also a greenhouse gas. The first feedback will be called the OH-feedback; the last two, together, will be called the radiative feedbacks.

There is considerable uncertainty regarding the strengths of these feedbacks. Estimates of the $\mathrm{OH}$ feedback and tropospheric ozone feedback are based on atmospheric models, but those models show that there is a complex relationship between a variety of tropospheric gases; the spatial distribution of various gases is a very important factor that affects tropospheric chemistry and the strength of the feedback. ${ }^{59}$ For example, tropospheric ozone formation is related to the spatial distribution of methane, other hydrocarbons, $\mathrm{CO}$, and $\mathrm{NO}_{\mathrm{x}}$ emissions. ${ }^{60} \mathrm{The}^{\mathrm{NO}} \mathrm{N}_{\mathrm{x}}$ dependence of ozone formation also heavily affects the strength of the $\mathrm{OH}$ feedback because ozone can itself react to produce $\mathrm{OH}$, offsetting some or all of the $\mathrm{OH}$-feedback. ${ }^{61}$ Thus the tropospheric $\mathrm{O}_{3}$ feedback and the $\mathrm{OH}$-feedback are $\mathrm{NO}_{x}$ dependent, and, to some extent, these feedbacks are inversely related: high tropospheric ozone formation offsets $\mathrm{OH}$ depletion. Further, the strength of radiative forcing - and thus the strength of the radiative feedback - depends on the altitudinal distribution of the radiatively active gases.

In a review of these and other feedbacks, Lashof has estimated that the $\mathrm{OH}$ feedback from methane emissions has the effect of adding an extra 0.5 moles of atmospheric methane for every 1 mole emitted (i.e. OH feedback factor of 1.5). $\mathrm{He}$ has also estimated that the direct radiative forcing of methane is increased $70 \%$ by indirect effects of increased tropospheric ozone and stratospheric water vapor forcing (i.e., radiative feedback factor of 1.7$){ }^{62}$ 
Given the uncertainties, the best-case scenario will assume that the feedbacks are overestimated and that the feedback factors are 1 (i.e., there are no feedbacks). Even as a best case this may be excessive since it seems that some level of such feedbacks will exist. However, this scenario is not entirely unreasonable: it is generally assumed that replacing gasoline-powered vehicles with NGVs will improve urban air quality (including lower urban ozone) and thus some of the methane feedbacks may be offset by the greenhouse advantages of lower urban ozone.

For the worst-case scenario, the feedback factors of Lashof are used, but the radiative feedback factor is increased to 2 on the assumption that current models under-predict the increase in tropospheric ozone due to increased methane concentrations. It is possible that the radiative feedback factor may even be higher. Owens et al. have estimated the feedback from tropospheric ozone, alone, at 1.7.63 For this scenario, the $\mathrm{OH}$ feedback factor remains at 1.5. If the radiative feedbacks are strong - especially the tropospheric ozone feedback - then it is difficult to imagine that the $\mathrm{OH}$ feedback factor will be very large since, as mentioned before, high ozone concentrations will probably offset at least some $\mathrm{OH}$ depletion.

Finally, for the intermediate scenario it is assumed that the $\mathrm{OH}$ feedback factor remains as described by Lashof but that the radiative feedback factor is lower, about 1.3 , because some of the feedbacks are offset by improved air quality and, generally, tropospheric ozone formation will be lower than predicted by the radiative chemical models used to deduce the higher radiative feedback factors.

The various leak rates and feedback factors used in the three scenarios are summarized in Table II.

TABLE II: Summary of leak scenarios

\begin{tabular}{ll}
\hline Scenarios and parameters & Value \\
\hline Best-case scenario & \\
$\quad$ Natural gas leak rate & $1 \%$ \\
Trop. $\mathrm{O}_{3}$ and strat. water-vapor feedback & 1 \\
OH-feedback & 1 \\
& \\
Worst-case scenario & $5 \%$ \\
$\quad$ Natural gas leak rate & 2 \\
Trop. $\mathrm{O}_{3}$ and strat. water-vapor feedback & 1.5 \\
OH-feedback & \\
& \\
Intermediate-case scenario & $2.5 \%$ \\
$\quad$ Natural gas leak rate & 1.3 \\
Trop. $\mathrm{O}_{3}$ and strat. water-vapor feedback & 1.5 \\
OH-feedback & \\
\hline
\end{tabular}




\subsection{Results}

Figure 8 shows the effects of leaking methane applied to the reference scenario with $60 \%$ NGV penetration. Five curves are shown: best case, worst case, intermediate case, and, for comparison, there is also a curve for the case if no NGVs are used and a curve if $60 \%$ NGVs are used but the leak rate is $0 \%$. For better resolution, the period 2030-2050 is enlarged and shown in Figure 9. The results are also reported in Table III, which also shows the percentage of greenhouse forcing due to methane for each scenario.

As before, when methane was not considered, the curves diverge over time; also, the curves respond sluggishly, primarily because the $\mathrm{CO}_{2}$ emissions are cumulated over time. By 2050, the increase in greenhouse forcing since 1950 under the worstcase scenario is $17 \%$ higher (4.02 ppm equiv.) than under the no NGVs scenario ( $3.44 \mathrm{ppm}$ equiv.). The best-case scenario is $4 \%$ lower ( $3.30 \mathrm{ppm}$ equiv.) than the no NGVs scenario. The intermediate scenario - using moderate leak rates and moderate feedback factors - is slightly higher (3.50 ppm equiv.) than if no NGVs

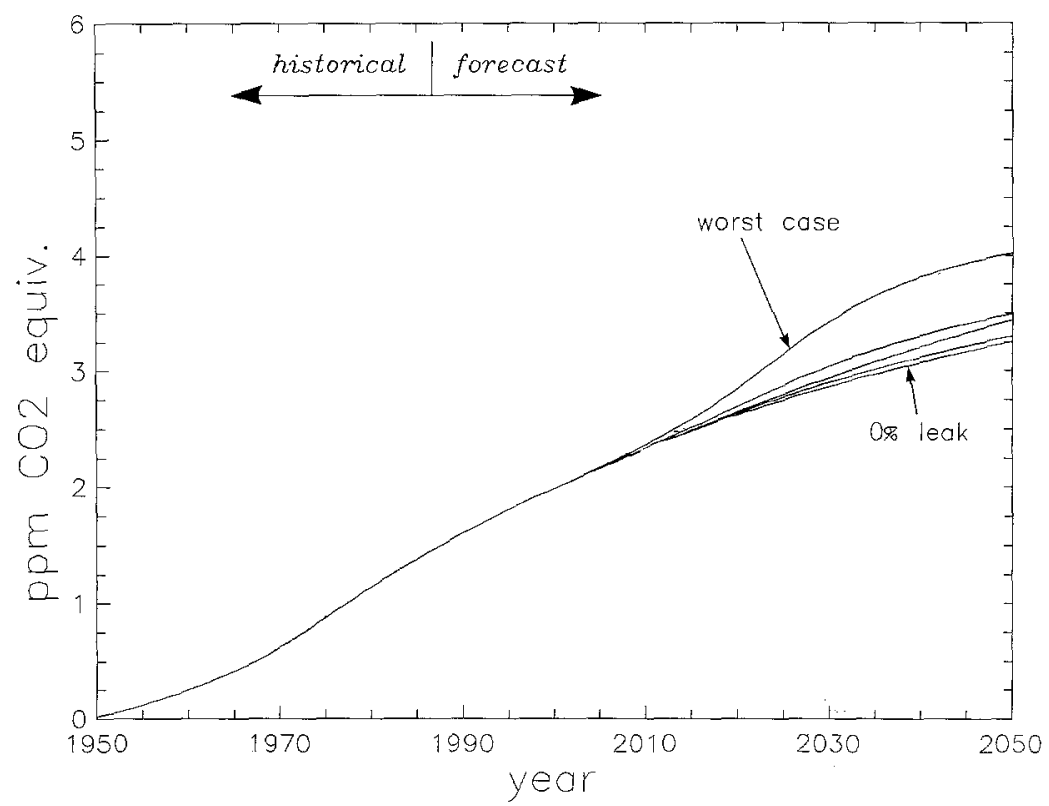

Fig. 8. Increase in atmospheric concentration of greenhouse gases $\left(\mathrm{CO}_{2}\right.$ and $\left.\mathrm{CH}_{4}\right)$ since 1950 due to automobile use in the United States using the reference scenario with $60 \% \mathrm{NGV}$ penetration. Concentrations expressed in $\mathrm{CO}_{2}$ equivalents, which is the sum of the increase in $\mathrm{CO}_{2}$ concentration since 1950 and the atmospheric methane concentration due to fossil-fuel use. Atmospheric methane concentrations are computed by the methane model described in the text and multiplied by 26 to convert ppm $\mathrm{CH}_{4}$ into ppm $\mathrm{CO}_{2}$. The methane concentrations are further multiplied by a chemical feedback factor (methane emissions are multiplied by an $\mathrm{OH}$-feedback factor). As described in the text, three scenarios are used to account for different leak rates and different feedback factors (scenarios summarized in Table II). These results also reported in Table III, along with the percentage greenhouse forcing due to methane. 
TABLE III: Total greenhouse forcing (in ppm $\mathrm{CO}_{2}$ equiv.) and percentage contribution of methane

\begin{tabular}{lcccccr}
\hline Scenario & \multicolumn{2}{c}{2000} & \multicolumn{2}{c}{2025} & \multicolumn{2}{c}{2050} \\
& Total & $\% \mathrm{CH}_{4}$ & Total & $\% \mathrm{CH}_{4}$ & Total & $\mathrm{CH}_{4}$ \\
\hline No NGVs & 1.99 & $0.0 \%$ & 2.79 & $0.0 \%$ & 3.44 & $0.0 \%$ \\
$0 \%$ leak & 1.99 & $0.0 \%$ & 2.75 & $0.0 \%$ & 3.25 & $0.0 \%$ \\
Intermed. case & 1.99 & $0.0 \%$ & 2.87 & $4.3 \%$ & 3.50 & $6.7 \%$ \\
Worst case & 1.99 & $0.1 \%$ & 3.15 & $12.6 \%$ & 4.02 & $18.7 \%$ \\
Best case & 1.99 & $0.0 \%$ & 2.77 & $0.9 \%$ & 3.30 & $1.4 \%$ \\
\hline
\end{tabular}

were used. This suggests that greenhouse forcing may increase if NGVs replace gasoline-powered vehicles. However, the range of outcomes is considerably narrower than under different demand assumptions (compare Figure 8 with Figure 7 ). All of the low-demand scenarios yield lower greenhouse forcing, and all of the high-demand scenarios yield substantially higher greenhouse forcing.

The curves and the results in Table III imply greater precision than actually exists since the uncertainties are extremely large. Fundamentally, there are major uncertainties in the leak rate, the feedback factors, and the method used for modelling atmospheric $\mathrm{CO}_{2}$. A large change in any one of these factors can significantly affect the relative greenhouse merits of NGVs and gasoline-powered vehicles. Nonetheless, the general conclusion remains. It is possible that greenhouse forcing into the middle of the next century may not decrease despite a vigorous NGV switching campaign. Forcing may even increase, and if the worst-case scenario is realized it may increase substantially.

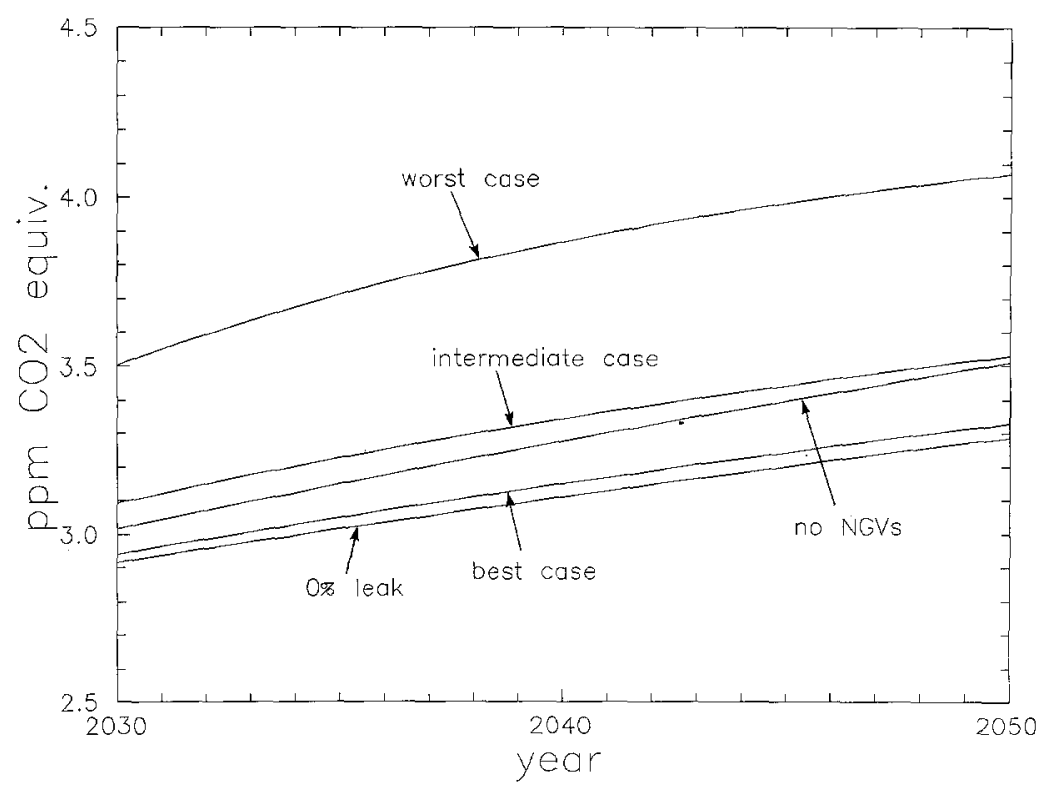

Fig. 9. Same as Fig. 8 but with better resolution for the period 2030-2050. 


\subsection{Oil Production and Associated Gas Leaks}

There is a difficult accounting problem in assigning natural gas leaks to various sources. The $3.6 \%$ leak rate based on atmospheric data is derived from an estimate of the total worldwide natural gas leaks; world natural gas production is divided into that figure to get $3.6 \%$. However, a considerable amount of natural gas is produced in associated wells and should be attributed to oil production rather than natural gas production. Whether or not the natural gas byproducts from these wells are used, such oil operations yield substantial methane leaks. For North America, the Arthur D. Little study found that the production leaks of natural gas were about evenly divided between the oil industry and the gas industry. ${ }^{64}$ Worldwide, about $80 \%$ of the leaks were attributed to the oil-production industry. ${ }^{65}$

Presumably most of the natural gas leaks from the oil industry would be accounted for in the Arthur D. Little study since it is expected that most of those leaks are in those areas they analyzed: (1) at or near the wellhead due to vented or incompletely flared associated gas, and (2) from refineries. Thus this may be a reasonable estimate for total natural gas leaks that are attributable to oil consumption (i.e., from wellhead to the end user of oil products). However, it does not follow that this is an accurate estimate of total natural gas leaks attributed to gas consumption because, as argued before, large gas leaks may be from interstate pipelines, end-distribution systems, and end users, which are not covered in the Arthur D. Little report. This suggests that the bulk of the natural gas leaks are still attributable to the natural gas industry. However, this is a highly contentious point.

Nonetheless, some attempt must be made to include leaks from oil operations. If the leaks from the oil industry are high, gasoline-powered vehicles would emit not only high levels of $\mathrm{CO}_{2}$ but also significant levels of $\mathrm{CH}_{4}$. This could work to the comparative advantage of NGVs, even if the NGVs also leak methane.

The Arthur D. Little study suggests the worldwide leaks of methane from oil and natural gas production are about $6.6 \mathrm{Tg} ;{ }^{66}$ of that, Arthur D. Little has attributed $5.3 \mathrm{Tg}$ to oil production. ${ }^{67}$ As just noted, this should be most of the leaks expected from oil production. However, perhaps the Arthur D. Little study has underestimated these leaks. Thus, in an effort to project a favorable case for NGVs, the $5.3 \mathrm{Tg}$ figure is doubled (10.6 Tg) to account for possibly unknown natural gas leaks which should be attributed to oil production.

Even when doubled, the leak rates for the oil industry are not large when compared with the gas industry. In 1987 , worldwide oil production was $123 \times 10^{18} \mathrm{~J}^{6}{ }^{68}$ dividing that number into the $10.6 \mathrm{Tg}$ of $\mathrm{CH}_{4}$ yields an average leak rate of $0.086 \mathrm{Tg}$ per $10^{18} \mathrm{~J}$ of oil production. For comparison, a $2 \%$ leak of annual natural gas production is $0.37 \mathrm{Tg}$ per $10^{18} \mathrm{~J}$ (about 4 times the oil leak rate). Thus even when oil sources of natural gas leaks are included, the leak rates from the natural gas industry appear much larger. However, it is not clear what the real leak rates are from either industry, so conclusions here are still premature. Further, the range of uncertainty in budgets presented by Cicerone and Oremland ${ }^{49}$ and others ${ }^{69}$ is 


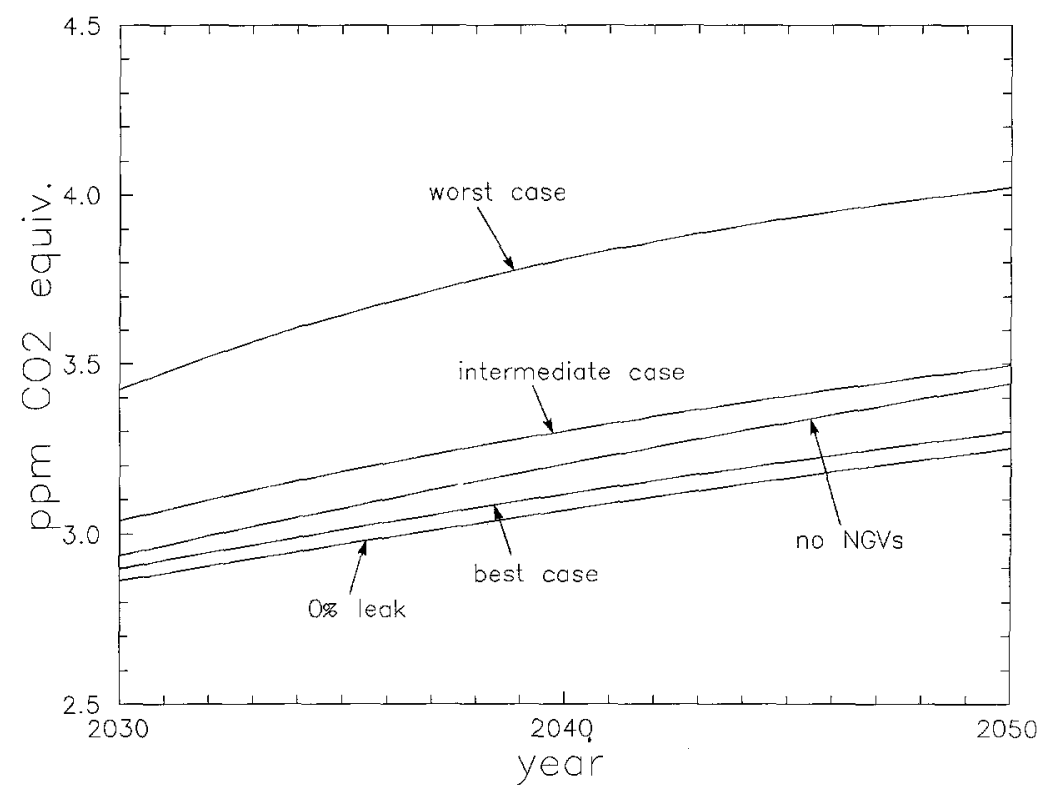

Fig. 10. Same as Fig. 9 but methane leaks from oil production are also estimated. As described in the text, what may be an extreme case is considered here in order to give the greatest comparative advantage to NGVs over gasoline-powered vehicles. These results are also reported in Table IV, along with the percentage greenhouse forcing due to methane.

sufficiently large that it is possible to construct a case where leakage from oil systems is high while leakage from gas production is extremely low (i.e., below $1 \%$ ). Under those assumptions, fuel switching from oil-based fuels to natural gas would always yield lower global warming.

Figure 10 reports the results for the five scenarios when this additional source of methane is included. The results are also summarized along with the percentage contribution of methane in Table IV. In general, all the curves are shifted slightly upward because of the additional forcing from additional methane leaks (compare with Figure 9 and Table III). However, the basic conclusions remain. The capacity

TABLE IV: Total greenhouse forcing (in ppm $\mathrm{CO}_{2}$ equiv.) and percentage contribution of methane; includes methane leaks attributed to oil consumption

\begin{tabular}{lcccccr}
\hline Scenario & \multicolumn{2}{c}{2000} & \multicolumn{2}{c}{2025} & \multicolumn{2}{c}{2050} \\
& Total & $\% \mathrm{CH}_{4}$ & Total & $\% \mathrm{CH}_{4}$ & Total & $\% \mathrm{CH}_{4}$ \\
\hline No NGVs & 2.09 & $4.4 \%$ & 2.87 & $2.5 \%$ & 3.51 & $1.6 \%$ \\
0\% leak & 2.09 & $4.4 \%$ & 2.81 & $2.0 \%$ & 3.29 & $0.8 \%$ \\
Intermed. case & 2.09 & $4.4 \%$ & 2.94 & $6.1 \%$ & 3.53 & $7.4 \%$ \\
Worst case & 2.13 & $6.7 \%$ & 3.24 & $14.9 \%$ & 4.07 & $19.4 \%$ \\
Best case & 2.06 & $3.4 \%$ & 2.82 & $2.4 \%$ & 3.33 & $2.0 \%$ \\
\hline
\end{tabular}

a Intermediate feedback values used for the 'no NGVs' and ' $0 \%$ leak' scenarios. 
to reduce greenhouse forcing in the near term through NGV switching is limited. ${ }^{70}$

Over the period of analysis considered here, the no-NGVs curve falls between the best case and the intermediate case; thus, the 'break-even' point is probably $1.5-2 \%$. However, as the $\mathrm{CO}_{2}$ benefits of using natural gas instead of oil-based fuels accumulate (i.e., as the period of analysis is extended), the case in favor of NGVs improves. This is reflected in the different shape of the 'no-NGVs' curve. These results are consistent with other studies. For electricity and combined heat production - where the efficiency advantages of natural gas over oil are even greater than those of NGVs over gasoline-powered automobiles - Wilson has computed a break-even point of 3-4\% for near-term (greenhouse forcing integrated over 20 years) analyses. ${ }^{71}$ Longer-term analyses (i.e., over 100 years) yield a much higher break-even point $(\approx 22 \%)$. Rodhe has computed a break-even point of $\approx 4 \%$ for long-term analyses, but that study did not consider the efficiency advantages of natural gas. ${ }^{72}$

\section{Conclusions}

In terms of VMT and fuel consumption, the U.S. automobile market grew dramatically from 1950 to 1975 . Since then, VMT has continued to grow while total fuel consumption (and greenhouse-gas emissions) have declined. If efficiency continues to improve into the future, fuel consumption will probably continue to decline (low-demand and reference scenarios). If efficiency stagnates and VMT continues to grow (high-demand scenario), primary fuel consumption will climb to nearly 4 times 1950 levels ( 1.5 times 1975 levels).

It is unlikely that the act of switching gasoline-powered vehicles to compressed natural gas will yield lower greenhouse forcing. Indeed, it is argued here that including the leaks from the natural gas system and NGVs themselves may reverse the greenhouse benefits of NGVs. Regardless, changes in greenhouse forcing due to methane leakage are relatively small when compared with the high- and lowdemand scenarios that show the greenhouse benefits of improving efficiency and constraining VMT growth. This is consistent with other studies that have shown the variety of promising options for dramatically increasing average efficiency in automobiles and reducing fuel consumption. ${ }^{73}$

This work suggests several policy-related areas for further research. First, there should be close consideration of the obstacles to identifying sources of methane leaks and the implications of such obstacles for the feasibility of a comprehensive treaty to control global warming. A fleet of NGVs will further disperse the sources of methane leakage and will add to the complexity of verifying a treaty. ${ }^{74}$

Second, comparisons of greenhouse forcing due to $\mathrm{CO}_{2}$ and non- $\mathrm{CO}_{2}$ emissions are highly dependent upon a number of controversial assumptions, notably the atmospheric lifetime of $\mathrm{CO}_{2}$. The computed break-even point for methane leakage can vary by a factor of two or more under different methodological assumptions regarding atmospheric retention of $\mathrm{CO}_{2}$. This must be kept in mind and will con- 
tinue to be one of the fundamental uncertainties that affects greenhouse policy analysis.

The method used here has assumed that the $\mathrm{CO}_{2}$ airborne fraction will remain constant. If the airborne fraction falls over time - which might be expected with these low demand scenarios (see ref. 42) - then the relative importance of leaking methane will rise. Additional studies in this area should compare the methods and parameters used to compute atmospheric concentrations and greenhouse forcing of the different gases. This is especially the case for $\mathrm{CO}_{2}$, whose complicated and uncertain response function is central to studies like the present one.

Third, it would be useful to analyze greenhouse-gas emissions in the context of more realistic transportation models such as those of Zahavi ${ }^{75}$ and Herman. ${ }^{76}$ Time budgets, money budgets, vehicle traffic quality, and other factors all contribute to consumer choices which, in turn, affect greenhouse-gas emissions and the cost-effectiveness of policy alternatives.

Fourth, a similar direction of research would be to compare estimated costs of reducing leaks with estimates of the cost of improving automobile fuel economy. ${ }^{77}$ The results presented here suggest that fuel economy improvements are probably much more cost-effective than would be efforts to tighten the natural gas supply and distribution system. However, extending this work to disaggregate the economic and social costs of efficiency improvements and VMT constraints may, in conjunction with the research described in the previous paragraph, provide important policy insights.

\section{Acknowledgements}

The author owes a special debt to J. H. Ausubel for encouraging and promoting this work and related research projects. Thank you, also, to W. C. Clark, A. Grübler, L. D. D. Harvey, H. Murray, N. Nakicenovic, J. Van de Vate, and M. A. Weiss for helpful comments on several drafts of this and a related paper and to C. Hogan and S. Reich for a copy of the Pacific Gas and Electric report. Comments from several anonymous reviewers were extraordinarily helpful in reworking the methane leak rates and the methane model. Research for this paper began with support from the MIT Energy Laboratory using funds received from Sandia National Laboratories. The modelling presented here was supported by a grant from the Center for International Studies at the Massachusetts Institute of Technology for three months of research at the International Institute for Applied Systems Analysis (IIASA). The author is grateful to C. Kaysen, A. McDonald, and E. B. Skolnikoff for helping to arrange the trip to IIASA. The final paper was completed, in part, with support as an adjunct research fellow with the Science, Technology and Public Policy Program at the John F. Kennedy School of Government. 


\section{Notes and References}

${ }^{1}$ In terms of grams of carbon per BTU: oil $=0.020256$, gas $=0.0144535$, and coal $=0.025109$; from J. A. Edmonds, W. B. Ashton, H. C. Cheng, and M. Steinberg, 1989, 'A Preliminary Analysis of U.S. $\mathrm{CO}_{2}$ Emissions Reduction Potential from Energy Conservation and the Substitution of Natural Gas for Coal in the Period to 2010', DOE/NBB-0085, U.S. Department of Energy. It is assumed in this analysis that oil products - gasoline in particular - have about the same emissions per BTU as oil. These numbers vary from source to source. For example they differ by $+1.5 \%$ for gas, $+5 \%$ for oil products (gasoline), and $+1 \%$ for bituminous coal from the carbon emission factors given in $G$. Marland, 1982, 'The Impact of Synthetic Fuels on Global Carbon Dioxide Emissions', in W. C. Clark (ed.), Carbon Dioxide Review: 1982, Oxford, New York: Roughly the same deviation exists $(+1 \%$ for gas, $+4.7 \%$ for oil, and $+2.1 \%$ for coal) when compared with data from R. M. Rotty and C. D. Masters, 1985, 'Carbon Dioxide from Fossil Fuel Combustion: Trends, Resources and Technological Implications; in J. R. Trabalka (ed.), Atmospheric Carbon Dioxide and the Global Carbon Cycle, ER-0239, Department of Energy, Washington. Emissions due to refining are included separately in the model.

${ }^{2}$ E.g. W. M. Burnett and S. D. Ban, 1989, 'Changing Prospects for Natural Gas in the United States', Science 244, 305-310.

${ }^{3}$ E.g. Testimony of M. Oppenheimer, 1989, Hearings before the Committee on Energy and Natural Resources, United States Senate, S. Hrg. 100-461, Pr. 2, p. 89.

${ }^{4}$ P. L. McGeer and E. J. Durbin, 1990, 'Natural Gas in Cars - and Step on It', New York Times, 2 October, A27.

${ }^{5}$ E.g. 'National Energy Policy Act of 1989', 101st Congress, S. 324, Sec. 1001-1008; 'Global Warming Prevention Act of 1989', 101st Congress, H.R. 1078, Sec. 703.

${ }^{6}$ About $26 \%$ of U.S. energy production is from natural gas, and the amount of gas-fired electricity is, for example, increasing. See Table 1.3 in Monthly Energy Review, Energy Information Agency, July ‘ 1988. (Although $26 \%$ of the energy is from gas, only $18 \%$ of U.S. $\mathrm{CO}_{2}$ production is due to gas.)

${ }^{7}$ J. H. Ausubel, A. Grübler, and N. Nakicenovic, 1988, 'Carbon Dioxide Emissions in a Methane Economy', Climatic Change 12, 245-263.

${ }^{8}$ NGVs have lower emissions of some pollutants than do gasoline automobiles; Italy has taken advantage of this as part of pollution-reduction programs. For recent work on $\mathrm{NO}_{\mathrm{x}}, \mathrm{CO}$, and $\mathrm{HC}$ emissions from NGVs as they pertain to local environmental concerns see, for example, Enoch J. Durbin, 1989, 'Understanding Emissions Levels from Vehicle Engines Fueled with Gaseous Fuels', Department of Mechanical and Aerospace Engineering, Princeton University. New Zealand, which is relatively well endowed with natural gas resources, has employed NGVs (and methane-derived synthetic gasoline) to* reduce the cost of oil imports and increase energy security. See D. Sperling, 1988, New Transportation Fuels: A Strategic Approach to Technological Change, University of California Press, Berkeley, pp. 9298.

${ }^{9}$ See 'National Energy Policy Act of 1989', S. 324 101st Congress., Sec. 2 (a) (5) for the role of fuel switching in GHG reductions and Sec. 1001-1006 on NGV research priorities.

${ }^{10}$ M. A. DeLuchi, R. A. Johnston, and D. Sperling, 1988, 'Transportation Fuels and the Greenhouse Effect', Transportation Research Record 1175, 33-44.

11 The general data source for 1950-1970 is U.S. Department of Commerce, 1975, Historical Statistics of the United States: Colonial Times to 1970, part 2, Govt. Printing Office, Washington. Data updated to 1985 from U.S. Department of Commerce: 1987, Statistical Abstract of the United Sta'es: 1988, Govt. Printing Office, Washington, and earlier editions of the same document. Throughout the present paper, citations are made to specific data sources used for the above two books.

123.838 million total highway mileage in 1975 and 3.862 total in 1985; from U.S. Federal Highway Administration, Highway Statistics. Total number of cars based on Motor Vehicle Manufacturer's Association estimates of cars in use. Data compiled in U.S. Dept. of Commerce, Statistical Abstract of the United States.

${ }^{13}$ American Public Transit Association, Transit Fact Book, annual publication summarized in Statistical Abstract of the United States: 1988, series no. 1011.

${ }^{14} 1950-1970$ VMT from U.S. Federal Highway Administration compiled in Historical Statistics of the United States, part 2, series Q 199-207; 1970-1985 VMT from U.S. Federal Highway Administration, Highway Statistics Summary to 1985, compiled in Statistical Abstract of the United States: 1988; histori- 
cal population data from U.S. Bureau of the Census, Current Population Reports. VMT for cars in 1970-1985 and passenger vehicles (cars plus buses) for 1950-1970. Buses never comprise more than $0.5 \%$ of passenger vehicles for the period 1950-1970 so errors from these accounting differences are probably very small.

${ }^{15}$ From 1984 data compiled in M. C. Holcomb, S. D. Floyd, and S. L. Cagle, 1987, Transportation Energy Data Book: Edition 9, ORNL-6325, Oak Ridge National Laboratory, Oak Ridge.

${ }^{16}$ Estimated 1986 driver's licenses were 158.594 million in a total population of 241.596 million. Source: U.S. Bureau of the Census and U.S. Federal Highway Administration, various publications, compiled in Statistical Abstract of the United States, series no. 2 and no. 991.

${ }^{17} \mathrm{OECD}$, 'Long Term Perspectives of the World Automobile Industry', note by the secretariat, November 1982, Annex I, pp. 5-7. Cited in A. Altshuler, M. Anderson, D. Jones, D. Roos, and J. Womack, 1984, The Future of the Automobile MIT Press, Cambridge, p. 110.

${ }^{18}$ The average growth rate for 1975-1985 (i.e., average growth in the post-oil shock period).

${ }^{19}$ Population forecasts from the World Bank. K. C. Zachariah and My. T. Vu, 1988, World Population Projections, 1987-88 Edition: Short- and Long-Term Estimates, Johns Hopkins Press, Baltimore.

${ }^{20}$ E.g. J. C. Fisher and R. H. Pry, 1971, 'A Simple Substitution Model of Technological Change', Technological Forecasting and Social Change 3, 75-88.

${ }^{21}$ The S-shaped curve is from an equation of the form

$$
\text { market fraction }=\frac{K}{1+\exp \left(-b\left(t-t_{0}\right)\right)},
$$

where $K$ is the maximum market fraction. $\Delta t$, the time it takes from penetration of $10 \%$ of the market (when $K=1)$ to $90 \%$ of the market, is 20 years. $b$ is a constant set in proportion to $\Delta t(b=0.2197$ for this model).

${ }^{22}$ For more on the standards and compliance see Council on Environmental Quality, Environmental Quality, published annually, Government Printing Office, Washington.

${ }^{23}$ See N. Nakicenovic, 1986, 'The Automobile Road to Technological Change', Technological Forecasting and Social Change 29, 309-340. This article addresses a series of technical innovations in the automobile industry.

${ }^{24}$ The age difference between $90 \%$ survival and $10 \%$ survival is about 10 years; thus a technology that affects new cars will diffuse into the market with that time constant. Survival data reported in M. C. Holcomb, S. D. Floyd, and S. L. Cagle 1987, Transportation Energy Data Book: Edition 9 ORNL6325, Oak Ridge National Laboratory, Oak Ridge.

${ }^{25}$ E.g. in $1978,51 \%$ of U.S. new car registrations were cars with engine size of 5.0 liters or greater ('very large'); that number dropped to $16 \%$ in 1982. International Energy Agency, 1984, Fuel Efficiency of Passenger Cars, OECD, Paris, p. 117.

${ }^{26}$ Data reported in G. Rosegger, 1989, 'Diffusion through Interfirm Cooperation: A Case Study', International Conference on Diffusion of Technologies and Social Behaviour, Laxenburg, Austria, 14-16 June, p. 11.

${ }^{27}$ From data compiled in M. C. Holcomb, S. D. Floyd, and S. L. Cagle, 1987, Transportation Energy Data Book: Edition 9, ORNL-6325, Oak Ridge National Laboratory, Oak Ridge.

${ }^{28}$ Using current data the model could not even reliably predict current fuel consumption. For this reason, projections were likely to be quite unrealistic.

${ }^{29}$ A. Altshuler et al., 1984. The Future of the Automobile MIT Press, Cambridge, ch. 5. Data on vehicle ownership updated with U.S. Highway Administration statistics.

${ }^{30} \mathrm{EPA}$ tests of existing automobiles converted to dual-fuel use found that burning natural gas gave about the same efficiency (BTU/mile) as an unconverted vehicle. Gasoline efficiency for the converted vehicle was about $10 \%$ lower. See R. I. Bruetsch, 1988, 'Emissions, Fuel Economy, and Performance of Light-Duty CNG and Dual-Fuel Vehicle', EPA/AA/CTAB-88-05.

${ }^{31}$ D. Sperling, 1988, New Transportation Fuels: A Strategic Approach to Technological Change, University of California Press, Berkeley, Table 37.

${ }^{32}$ For recent work on $\mathrm{NO}_{x}, \mathrm{CO}$, and $\mathrm{HC}$ emissions from NGVs see Enoch J. Durbin, 1989, 'Understanding Emissions Levels from Vehicle Engines Fueled with Gaseous Fuels', Princeton University, Department of Mechanical and Aerospace Engineering. My study does not address the effect on NGV efficiency of pollution-control equipment such as catalytic converters.

${ }^{33} 7.5 \%$ for refining, which includes net transfers to petroleum refineries (i.e., consumption during 
refining), of 0.13 mtoe (million tons oil equiv.) coal, 13.85 mtoe gas, 2.92 mtoe electricity, and 38.47 mtoe oil; coal, gas, and electricity corrected for different carbon contents (elect. based on 1986 fuel mix and generation efficiency). $0.5 \%$ for 'own use', which includes oil pipeline consumption and energy required for oil extraction ( $0.5 \%$ for indigenous U.S. production for oil). Computed from 1986 OECD statistics for the United States. OECD, 1988, Energy Balances of OECD Countries OECD, Paris, p. 120.

${ }^{34}$ Calculated from 1986 data in Table 13, Energy Information Administration, 1988, Natural Gas Annual 1987, vol. 1 U.S. Government Printing Office, Washington.

${ }^{35}$ Includes consumption for pipeline operations and gas extraction. Computed from 1986 OECD statistics for the United States, Energy Balances of OECD Countries, OECD, Paris, p. 120.

${ }^{36}$ These fractions for 'own use' do not include gas consumed for reservoir repressuring sincetliat gas is not burned and, therefore, does not yield $\mathrm{CH}_{4}$ emissions.

${ }^{37}$ B. Bolin, 1986, 'How Much $\mathrm{CO}_{2}$ Will Remain in the Atmosphere', in Bolin, B., Döös, B. R., Jäger, J., Warrick, R. A. (eds.), The Greenhouse Effect, Climatic Change, and Ecosystems, SCOPE 29, Wiley, New York.

${ }^{34}$ E.g. W. D. Nordhaus and G. W. Yohe, 1983, 'Future Carbon Dioxide Emissions, from Fossil Fuels', in NRC, Changing Climate, National Academy Press, Washington, pp. 87-153. Because the Nordhaus and Yohe projections extend quite far into the future (until 2100) they have also used a slow seepage factor. They find (p. 129) that the maximum likelihood marginal airborne fraction is: $47 \%$.

${ }^{39}$ D. A. Lashof and D. R. Ahuja, 1990, 'Relative contributions of Greenhouse Gas Emissions to Global Warming', Nature 344, 5:29-531.

${ }_{4}^{4}$ D. J. Wuebbles and J. Edmonds, 1988, A Primer on Greenhouse Gases, DOE/NBB-0083, p. 9.

${ }^{41}$ As done by Nordhaus and Yohe, 1983. See note 38.

${ }^{42}$ It has been suggested that this transient relationship between anthropogenic $\mathrm{CO}_{2}$ emissions and the airborne fraction be explored in a public policy which manages atmospheric $\mathrm{CO}_{2}$ concentrations. See L. D. D. Harvey, 1989, 'Managing Atmospheric $\mathrm{CO}_{2}$ ', Climatic Change 15, 343-3.81.

${ }^{43}$ Greenhouse trapping calculated by computing the molar quantity of $\mathrm{CO}_{2}$ that remains airborne and then assuming an atmosphere that weighs $5.137 \times 10^{18} \mathrm{~kg}$ and has molecular weight of $28.96 \mathrm{~g} / \mathrm{mole}$ $\left(1.77 \times 10^{20}\right.$ moles total). All concentrations done by volume, not mass.

${ }_{4}^{44}$ The marginal greenhouse forcing from an additional $\mathrm{ppm}$ of $\mathrm{CH}_{4}$ compared with an additional ppm of $\mathrm{CO}_{2}$ highly depends on the concentration of the two (and other gases). At higher concentrations, the marginal effect of a gas decreases due to band saturation. The increase in concentrations used for this calculation is $250-350 \mathrm{ppm}$ for $\mathrm{CO}_{2}$ and 1.7-2.7 ppm for $\mathrm{CH}_{4}$. Calculations as shown in D. A. Lashof and D. R. Ahuja, supra note 39. (A value of 26 is derived by removing the $70 \%$ feedback factor from the value for methane shown in Lashof and Ahuja's Table 1 and then computing the ratio of $\mathrm{CH}_{4}$ to $\mathrm{CO}_{2}$.) This number is consistent with the marginal greenhouse forcing due to a range of possible $\mathrm{CO}_{2}$ increases as shown in D. A. Lashof, 1989, 'The Dynamic Greenhouse: Feedback Processes That May Influence Future Concentrations of Atmospheric Trace Gases and Climatic Change', Climatic Change 14, 213-242. The results in these two papers are based on the model presented in J. Hansen, I. Fung, A. Lacis, D. Rind, S. Lebedeff, R. Ruedy, G. Russell, and P. Stone, 1988, 'Global Climate Changes as Forecast by Goddard Institute for Space Studies Three-Dimensional Model', Journal of Geophysical Research 93, 9341-9364.

1. W. P. Linak, J. A. McSorley, R. E. Hall, J. V. Ryan, R. K. Srivastava, J. O. L. Wendt, and J. B. Mereb, 1990, 'Nitrous Oxide Emissions from Fossil Fuel Combustion', Journal of Geophysical Research 95, 7533-7541. However, indirect emissions of $\mathrm{N}_{2} \mathrm{O}$ due to acid precipitation caused by fossil-fuel combustion may be significant. See J. W. Elkins, 1989, 'State of the Research for Atmospheric Nitrous Oxide $\left(\mathrm{N}_{2} \mathrm{O}\right)$ in 1989', contribution to the Intergovernmental Panel on Climate Change (IPCC).

$469.6(+2.2,-1.5)$ years, rounded to one significant digit. Reported in R. Prinn, D. Cunnold, R. Rasmussen, P. Simmonds, F. Alyea, A. Crawford, P. Fraser, and R. Rosen, 1987, Atmospheric Trends in Methylchloroform and the Global Average for the Hydroxyl Radical', Science 238, 945-950.

${ }^{47}$ See the discussion in Lashof and Ahuja (note 39) and in E. Maier-Reimer and K. Hasselmann, 'Transport and Storage of $\mathrm{CO}_{2}$ in the Ocean - An Inorganic Ocean Circulation Carbon Cycle Model', Climate Dynamics 2, 63-90.

${ }^{48}$ Lashof and Ahuja use 230 years but also compute sensitivity to a discount rate (see note 39); Wilson uses 100 years (see note 71); Rodhe uses 120 years (see note 72); Wuebbles and Edmonds use 500 years (see note 40 ). Elsewhere, the author has argued for a variety of possible lifetimes, depending on 
the temporal pattern of $\mathrm{CO}_{2}$ emissions and on certain carbon-cycle assumptions (D. G. Victor, 1990, 'Calculating Greenhouse Budgets', Nature 347, 431). The fixed airborne fraction method is valid for exponentially increasing emissions and is consistent with a relatively short atmospheric lifetime for $\mathrm{CO}_{2}$ (see note 37).

${ }^{49}$ R. J. Cicerone and R. S. Oremland, 1988, 'Biogeochemical Aspects of Atmospheric Methane', Global Biogeochemical Cycles 2, 299-327.

${ }^{50}$ D. R. Blake and F. S. Rowland, 1988, 'Continuing Worldwide Increase in Tropospheric Methane', Science 239, 1129-1131. Slightly lower values are reported for the two-year period 1983-1985 in L. D. Steele, P. J. Fraser, R. A. Rasmussen, M. A. K. Khalik, T. J. Conway, A. J. Crawford, R. H. Gammon, K. A. Masarie, and K. W. Thoning, 1987, 'The Global Distribution of Methane in the Troposphere', Journal of Atmospheric Chemistry 5, 125-171.

$5132 \%$ reported in D. C. Lowe, C. A. M. Brenninkmeijer, M. R. Manning, R. Sparks, and G. Wallace, 1988, 'Radiocarbon Determination of Atmospheric Methane at Baring Head, New Zealand', Nature 332, 522-525. A minimum of $15 \%$ is reported in M. Wahlen, N. Tanaka, R. Henry, B. Deck, J. Zeglen, J. S. Vogel, J. Southon, A. Shemesh, R. Fairbanks, and W. Broecker, 1989, 'Carbon-14 in Methane Sources and in Atmospheric Methane: The Contribution from Fossil Carbon', Science 245, 286-290.

${ }_{52}$ British Petroleum, 1989, BP Statistical Review of World Energy, 1989. Carbon content of natural gas (used to convert to $\mathrm{Tg}$ of $\mathrm{CH}_{4}$ ) from R. M. Rotty and C. D. Masters, 1985, 'Carbon Dioxide from Fossil Fuel Combustion: Trends, Resources, and Technological Implications', in J. R. Trabalka (ed.), Atmospheric Carbon Dioxide and the Global Carbon Cycle, DOE/ER-0239, Department of Energy, Washington.

${ }^{53}$ Pacific Gas and Electric, 1989, 'Before the Public Utilities Commission of the State of California', Application No. 89-04-001 dated 31 July, especially E1-E13. See also 'Leak Task Force', supporting documents, vol. 4.

${ }^{54}$ Arthur D. Little, 1989, 'Methane Emissions from the Oil and Gas Production Industries', final report to Ruhrgas A. G., reference 63193, esp. pp. 9-11 (English text).

55 American Gas Association, 1986, 'Lost and Unaccounted for Gas', Planning and Analysis issues, issue brief $1986-28$, p. 3. This paper also reviews a 1986 General Accounting Office (GAO) study which found that the average leak rate for 92 gas distribution companies was $15 \%$. However, those 92 companies only accounted for $0.2 \%$ of the gas delivered in the U.S.

${ }^{56} 1987$ 'unaccounted for' gas data as percentage of total supply/disposition. EIA, 1988, Monthly Energy Review, May, p. 63.

${ }^{57}$ OECD, 1988, Energy Balances of OECD Countries, OECD, Paris, p. 120.

${ }^{58}$ However, it appears that much of that work is directed at gas industry leaks in Western countries. It is implied in this paper that the most substantial leaks may be elsewhere, in other countries and/or gas consumers.

${ }^{59}$ For reviews of tropospheric chemistry see J. H. Seinfeld, 1989, 'Urban Air Pollution: State of the Science', Science 243, 745-752. J. A. Logan, 1985, 'Tropospheric Ozone: Seasonal Behavior, Trends, and Anthropogenic Influence,, Journal of Geophysical Research 90, 10 463-10 482.

${ }^{60}$ A. M. Thompson, R. W. Stewart, M. A. Owens, and J. A. Herwehe, 1989, 'Sensitivity of Tropospheric Oxidants to Global Chemical and Climate Change', Atmospheric Environment 23, 519-532.

${ }^{61}$ A. M. Thompson and R. J. Cicerone, 1986, 'Possible Perturbations to Atmospheric $\mathrm{CO}, \mathrm{CH}_{4}$, and OH', Journal of Geophysical Research 91, 10 853-10 864.

${ }^{62}$ D. A. Lashof, 1989, 'The Dynamic Greenhouse: Feedback Processes That May Influence Future Concentrations of Atmospheric Trace Gases and Climate Change', Climatic Change 14, 213-242.

${ }_{6.3}^{3}$ A. C. Owens, C. H. Hales, D. L. Filkin, C. Miller, J. M. Steed, and J. P. Jesson, 1985, A Coupled One-Dimensional Radiative-Convective Chemistry-Transport Model of the Atmosphere, 1, Model Structure and Steady State Perturbation Calculations', Journal of Geophysical Research 90, 2283 2311. Cited in V. Ramanathan, L. Callis, R. Cess, J. Hansen, I. Isaksen, W. Kuhn, A. Lacis, F. Luther, J. Mahlman, R. Reck, and M. Schlesinger, 1987, 'Climate-Chemical Interactions and Effects of Changing Atmospheric Trace Gases', Reviews of Geophysics 25, 1441-1482.

${ }^{64}$ Production leaks are natural gas leaks due to the exploration and recovery of oil (and associated gas) and non-associated natural gas. The category encompasses a variety of production-related leaks, including: flaring/venting, well blowouts, wellhead equipment leakage, and oil refinery operations. It does not include pipeline leaks, end-distribution systems leaks, and end-user leaks.

${ }^{65}$ Arthur D. Little assigned all associated gas production to the oil industry; about $30 \%$ of worldwide 
gas production is associated. It is not rigorously correct to assign all of the leaks from associated gas to the oil industry since that gas is used and burnt as natural gas. However, it is not clear what the methodology should be here.

${ }^{66}$ Computed by calculating the worldwide leak rate entirely from Arthur D. Little's statistics (to retain internal consistency). That number is $0.53 \%$. The budget in Cicerone and Oremland assigns $45 \mathrm{Tg}$ to natural gas leaks, or about $3.6 \%$ of world production (using BP energy statistics). Prorating, the $0.53 \%$ leak rate reported by Arthur D. Little corresponds with world leakage of $6.6 \mathrm{Tg}$.

${ }^{67}$ World oil production is used here since the U.S. imports about half of its oil. However, this may overestimate the methane leaks due to U.S. oil consumption since about $1 / 4$ of methane emissions from the oil industry are from Eastern Europe (according to the Arthur D. Little study). The U.S. imports essentially no oil from Eastern Europe.

${ }^{68}$ British Petroleum, 1988, BP Statistical Review of World Energy BP, London, p. 4. 1987 chosen for this analysis because the Arthur D. Little study uses 1987 data.

${ }^{69}$ E.g. Methane Emissions and Opportunities for Control, Workshop results of Intergovernmental Panel on Climate Change, Response Strategies Working Group (1990). Available from the U.S. Environmental Protection Agency.

${ }^{70}$ Some may argue that the results are purely an artifact of the airborne-fraction method used for calculating atmospheric $\mathrm{CO}_{2}$ concentrations. If the airborne fraction were higher, it might be argued, greenhouse forcing from $\mathrm{CO}_{2}$ would be relatively more important and less $\mathrm{CO}_{2}$-intensive technologies (such as NGVs) would have an even greater greenhouse advantage. While true, increases in the airborne fraction do not undermine the essential conclusions presented here. The model was tested with a $100 \%$ airborne fraction - an absolutely unlikely and excessive case - and the conclusion that NGVs can have a limited effect remains. In 2050 , the worst-case scenario is still $5 \%$ above the no NGVs scenario. The intermediate-case scenario, however, is $2 \%$ below the no NGVs scenario. Initially, greenhouse forcing from the intermediate case is higher, but in 2030 the no NGVs scenario has equal forcing and then rises above the intermediate case scenario thereafter.

${ }^{71}$ D. Wilson, 1990, 'Quantifying and Comparing Fuel-Cycle Greenhouse-Gas Emissions', Energy Policy 18, 550-562; see her Table 8 and note 51. Her study (which includes $\mathrm{N}_{2} \mathrm{O}$ emissions) analyzes several different options for achieving equal output of heat and electricity. To derive a break-even point she contrasts greenhouse-gas emissions from 10 oil-fired steam turbines and 4 oil-fired combinedcycle gas turbines with the emissions from 10 gas-fired combined-cycle gas turbines. In addition to analysis of a different sector, Wilson's estimated break-even point is higher than the one presented here because she integrates future warming assuming a 100-year atmospheric lifetime for $\mathrm{CO}_{2}$ emissions whereas the present study uses the airborne-fraction method. This paper does not consider direct $\mathrm{N}_{2} \mathrm{O}$ emissions from fossil-fuel combustion because they are no longer believed to be significant (see note 45). Wilson also explores greenhouse emissions due to coal; she computes the break-even leakage for gas at $5.9 \%$ for short-term (20 year integration) comparisons. See also C. G. James, 1990, 'Natural Gas and the Greenhouse', Nature 347, 720. James computes a coal/gas break-even point of $4.9 \%$ leakage for a 20-year time horizon.

${ }^{72} \mathrm{H}$. Rodhe, 1990, 'A Comparison of the Contribution of Various Gases to the Greenhouse Effect', Science 248, 1217-1219. Rodhe's calculations are based on a 120-year residence time for $\mathrm{CO}_{2}$.

${ }^{73}$ E.g. J. Goldemberg, T. B. Johansson, A. K. N. Reddy, and R. H. Williams, 1987, Energy for a Sustainable World, World Resources Institute, Washington. A longer version of this is published by WileyEastern, New Delhi (1988). See also D. L. Bleviss, 1988, The New Oil Crisis and Fuel Economy Technologies: Preparing the Light Transportation Industry for the 1990s, Quorum Books, New York, esp. pp. $19-116$.

${ }^{74}$ For more on obstacles to verifying an international greenhouse treaty see D. G. Victor, 1990, 'Limits of Market-Based Strategies for Slowing Global Warming', Policy Sciences 24, 199-222.

${ }^{75}$ Y. Zahavi, 1981, 'The UMOT Model', U.S. Department of Transportation, Rēseārch and Special Programs Administration (May).

${ }^{76}$ E.g. R. Herman and S. Ardekani, 1985, 'The Influence of Stops on Vehicle Fuel Consumption in Urban Traffic', Transportation Science 19, 1-12.

${ }^{77}$ E.g. C. Difiglio, K. G. Duleep, and D. L. Greene, 1990, 'Cost Effectiveness of Future Fuel Economy Improvements', The Energy Journal 11, 65-86.

(Received 17 August, 1989; in revised form 5 November, 1990) 